\title{
Laser desorption ionization time-of-flight mass spectrometry of erbium doped Ga-Ge-Sb-S glasses
}

Sachinkumar Dagurao Pangavhane ${ }^{1}$, Petr $\mathrm{Němec}^{2} *$, Virginie Nazabal ${ }^{3}$, Alain Moreac ${ }^{4}$, Pál Jóvári $^{5}$ and Josef Havel ${ }^{1,6,7}$

${ }^{1}$ Department of Chemistry (A14/107), Faculty of Science, Masaryk University, Kamenice 753/5, Bohunice, 62500 Brno, Czech Republic

${ }^{2}$ Department of Graphic Arts and Photophysics, Faculty of Chemical Technology, University of Pardubice, 53210 Pardubice, Czech Republic

${ }^{3}$ ISCR, Glasses and Ceramics team, UMR-CNRS 6226, University of Rennes 1, 35042 Rennes, France

${ }^{4}$ UMR CNRS 6251, Institut de Physique de Rennes, Université de Rennes 1, 35042 Rennes, France

${ }^{5}$ Institute for Solid State Physics and Optics, Wigner Research Centre, Hungarian Academy of Sciences, H-1525 Budapest, POB 49, Hungary

${ }^{6}$ Department of Physical Electronics, Faculty of Science, Masaryk University, Kotlářská 2, 611

37 Brno, Czech Republic

${ }^{7}$ R\&D Center for Low-Cost Plasma and Nanotechnology Surface Modifications, Masaryk University, Kotlářská 2, 61137 Brno, Czech Republic

RATIONALE: Rare earth doped sulphide glasses in the Ga-Ge-Sb-S system present radiative emissions from visible to the middle infrared range (mid-IR) range, which are of interest for a variety of applications including (bio)-chemical optical sensing, light detection and ranging, and military counter-measures. The aim of this work is to reveal structural motifs present during fabrication of thin films by plasma deposition techniques; such knowledge is important for the optimization of thin films growth.

METHODS: Formation of clusters in plasma plume from different concentration of erbium doped $\mathrm{Ga}_{5} \mathrm{Ge}_{20} \mathrm{Sb}_{10} \mathrm{~S}_{65}$ glasses (0.05, 0.1, and 0.5 wt. \% of erbium) using laser (337 nm) desorption ionization (LDI) was studied by time-of-flight mass spectrometry (TOF MS) in both, positive and negative ion modes. The stoichiometry of the $\mathrm{Ga}_{m} \mathrm{Ge}_{n} \mathrm{Sb}_{o} \mathrm{~S}_{p}^{+/}$clusters was determined via isotopic envelope analysis and computer modelling.

RESULTS: A number of $\mathrm{Ga}_{m} \mathrm{Ge}_{n} \mathrm{Sb}_{o} \mathrm{~S}_{p}{ }^{+-}$singly charged clusters was found, but surprisingly, only four species $\left(\mathrm{Sb}_{3} \mathrm{~S}_{4}{ }^{+/-}, \mathrm{Ga}_{m} \mathrm{Sb}_{o} \mathrm{~S}_{p}{ }^{+/-}(m=1, o=2, p=4,5), \mathrm{Ga}_{3} \mathrm{Sb}_{2} \mathrm{~S}_{7}{ }^{+/-}\right)$were common to both ion modes. For the first time, species containing rare earths $\left(\mathrm{GaSb}_{2} \mathrm{SEr}^{+}\right.$and $\left.\mathrm{GaS}_{6} \mathrm{Er}_{2}{ }^{+}\right)$were identified in plasma formed from rare earth doped chalcogenide glasses, directly confirming importance of gallium presence for rare earths bonding within the glassy matrix.

CONCLUSIONS: The local structure of Ga-Ge-Sb-S glasses is at least partly different from the structure of species identified in plasma by mass spectrometry, as deducted from Raman scattering spectroscopy analysis; it is mainly formed by $\left[\mathrm{GeS}_{4 / 2}\right] /\left[\mathrm{GaS}_{4 / 2}\right]$ tetrahedra and $\left[\mathrm{SbS}_{3 / 2}\right]$ pyramids. $\mathrm{Er}^{3+}$ ions in Ga-Ge-Sb-S glasses are surrounded by 7 sulphur atoms as concluded from Extended X-ray absorption fine structure measurements.

KEYWORDS: time-of-flight mass spectrometry; Raman spectroscopy; chalcogenide glass; erbium dopant; EXAFS

* Correspondence to: Petr Němec, Department of Graphic Arts and Photophysics, Faculty of Chemical Technology, University of Pardubice, 53210 Pardubice, Czech Republic

E-mail: petr.nemec@upce.cz 


\section{INTRODUCTION}

Amorphous chalcogenides are today's exciting field for innovations; their widespread technological applications (either the bulk glasses or thin films) are holding scientists attention and forcing them to look for upcoming challenges and demands in the field of infrared optics, photonics, development of next generation computer memories, and recently emerging their applications in the field of medical, military, and aerospace. ${ }^{[1-7]}$ The applications of amorphous chalcogenides are based on their specific properties when compared to classical silica glass: wide IR transparency (up to $12 \mu \mathrm{m}$ for sulphides and up to $16 \mu \mathrm{m}$ for selenides), low phonon energy ( $350 \mathrm{~cm}^{-1}$ for sulphides and $\sim 250 \mathrm{~cm}^{-1}$ for selenides), photosensitivity, high linear/non linear refractive index, etc. ${ }^{[8]}$

Rare earth doped chalcogenide glasses are intensively studied for several years. Low phonon energy of chalcogenide glasses affords low probability of multiphonon relaxations among the energy levels of rare earth ions. Therefore, radiative efficiencies of the most rare earth emissions in near and mid-IR are improved. Many radiative transitions in the near/mid-IR have been observed in bulk chalcogenide glasses doped with single rare earth ions, for example, $\mathrm{Pr}^{3+}, \mathrm{Tb}^{3+}$, $\mathrm{Dy}^{3+}, \mathrm{Ho}^{3+}{ }^{[9-16]}$ or co-doped like $\mathrm{Tm}^{3+} / \mathrm{Tb}^{3+}$ or $\mathrm{Nd}^{3+} / \mathrm{Tm}^{3+}$ for instance. ${ }^{[17,18]}$ Rare earth doped Ga-Ge-Sb-S glasses possess suitable thermo-mechanical properties for optical fiber drawing or integrated waveguides fabrication. The presence of antimony improves the glass properties of Ga-Ge-S system. ${ }^{[19]}$ Further, Ga-Ge-Sb-S glasses contain gallium which allows significantly better solubility of rare earths within the glass matrix. Bulk glasses, conventional fibers and rib/ridge waveguides were already fabricated to explore the potentiality of this system. ${ }^{[20-27]}$ Among the rare earths, erbium possesses a large variety of transitions from visible to mid-IR emissions; of interest are especially transitions at 2.8 and $4.5 \mu \mathrm{m}$. Recently, pulsed laser deposition (PLD) technique has been applied for the fabrication of erbium doped $\mathrm{Ga}_{5} \mathrm{Ge}_{20} \mathrm{Sb}_{10} \mathrm{~S}_{65}$ thin films. ${ }^{[28]}$

Laser Desorption Ionization Time-of-Flight Mass Spectrometry (LDI-TOF MS) was recently shown to be suitable and effective method for the generation and study of clusters formed by laser ablation of various solid materials such as nano-diamonds, ${ }^{[29]} \mathrm{AgSbS}_{2},{ }^{\left[{ }^{[30]}\right.}$ As-sulphides, ${ }^{[31]}$ $\mathrm{P}_{p} \mathrm{~S}_{q} \mathrm{Se}_{r},{ }^{[32]} \mathrm{AsS}_{n}{ }^{+}(n=1-7),{ }^{[33]} \alpha-\mathrm{P}_{3} \mathrm{~N}_{5}{ }^{[34]}$ or nano aluminium nitride. ${ }^{[35]}$ TOF MS was successfully used to analyze chalcogenide glasses such as As-Se or As-S-Se; ${ }^{[36,37]}$ it was found that this technique is suitable for determining the structural fragments of such solid materials. The aim of this work is to study the formation of clusters from quaternary Ga-Ge-Sb-S glasses doped with erbium using LDI-TOF MS in order to obtain a better understanding of the structural fragments present in the plasma plume. The knowledge gained should contribute to a better understanding of the fabrication and properties of thin films prepared by plasma deposition techniques, especially by PLD.

\section{EXPERIMENTAL SECTION}

\section{Chemicals}

Elemental gallium, germanium, antimony, sulphur (99.999 \% purity) and erbium (99.9 \% purity) were purchased from Strem Chemicals, Inc. (Boston, Massachusetts, USA) or Umicore (Brussels, Belgium). Red phosphorus was purchased from Riedel de Haën (Hannover, Germany) and was used for mass calibration. Water was doubly distilled using a quartz apparatus from Heraeus Quartzschmelze (Hanau, Germany). Acetonitrile and toluene was purchased from Penta Chemicals (Mainaschaff, Germany). All other reagents were of analytical grade purity. Parafilm 'M' was purchased from the Pechiney Plastic Packaging Company (Chicago, IL, USA).

\section{Sample preparation}


Non-doped Ga-Ge-Sb-S and erbium doped (0.05, 0.1, and 0.5 wt. \% of $\mathrm{Er}^{3+}$, eventually 1 wt. \% of $\mathrm{Er}^{3+}$ for Extended X-ray absorption fine structure measurements) $\mathrm{Ga}_{5} \mathrm{Ge}_{20} \mathrm{Sb}_{10} \mathrm{~S}_{65}$ glasses were prepared by conventional melting and quenching method. Above mentioned, high purity raw materials were used for the glasses synthesis. However, commercial sulphur was further purified by successive distillations to limit carbon and hydrates or sulphide hydride impurities. ${ }^{[8]}$ Then, the required amounts of chemical reagents were introduced in silica ampoules; afterwards evacuated and sealed silica tubes were heated at $850{ }^{\circ} \mathrm{C}$ for 12 hours in a rocking furnace to ensure the homogenization of the melt. After water quenching, the glass rods were annealed near, but below their glass transition temperatures for 6 hours. For energy-dispersive X-ray analysis (EDX), X-ray diffraction (XRD) measurements, optical transmission, and Raman scattering spectroscopy, polished samples of prepared glasses were used.

\section{Instrumentation}

The chemical composition of prepared glasses was characterized using scanning electron microscopy using JSM 6400 instrument, JEOL Ltd. (Tokyo, Japan) connected with EDX analyzer. XRD data were obtained with a D8-Advance diffractometer from Bruker AXS (Karlsruhe, Germany) with Bragg-Brentano $\theta-\theta$ geometry (40 kV, $40 \mathrm{~mA}$ ) using $\mathrm{CuK} \alpha$ radiation with secondary graphite monochromator. The diffraction angles were measured at room temperature from 5 to $65^{\circ}(2 \theta)$ in $0.02^{\circ}$ steps with a counting time of $5 \mathrm{~s}$ per step. The optical transmission of the polished samples was measured from 400 to $3200 \mathrm{~nm}$ using Lambda 1050 spectrophotometer, Perkin-Elmer (Waltham, Massachusetts, USA).

Raman scattering spectra were collected at room-temperature by double-monochromator Raman spectrophotometer HR800 from Horiba Jobin-Yvon (Longjumeau, France) with 785 nm laser diode as excitation source. Light intensity of laser beam on the sample was kept at low level (to avoid changes of Raman spectra due to thermally-induced structural transformations induced by absorption of high laser power densities) by optical density filters. Extended X-ray absorption fine structure (EXAFS) of powdered glass was recorded at LIII-edge of $\mathrm{Er}$ at SAMBA beamline at SOLEIL synchrotron (Saint-Aubin, France). The EXAFS measurements were recorded using a liquid $\mathrm{N}_{2}$ cryostat and fluorescence modes. Raw intensities were converted into $\chi(\mathrm{k})$ curves by the Viper program. ${ }^{[38]}$ Coordination numbers, bond lengths, and Debye-Waller factors were obtained by fitting the $\chi(\mathrm{k})$ curves with the Viper program. Backscattering amplitudes and phases needed to calculate the model curves were obtained by the Feff program. $^{\text {[39] }}$

Mass spectra were measured employing AXIMA CFR mass spectrometer from Kratos Analytical (Manchester, UK). TOF MS was equipped with nitrogen laser from Laser Science Inc. (Franklin, MA, USA) and operated at a wavelength of $337 \mathrm{~nm}$. Mass spectra were measured as intensity of ions vs. $\mathrm{m} / \mathrm{z}$ (mass/charge). The repetition modes of experiments were performed at a frequency of $10 \mathrm{~Hz}$ and a pulse width of $3 \mathrm{~ns}$. The laser fluence was $1 \mathrm{~J} / \mathrm{cm}^{2}$. Full laser power as indicated on the instrument was 180 a.u. (arbitrary units) while the irradiated spot size was approximately $150 \mu \mathrm{m}$ in diameter. The laser power can be varied between 0 and 180 a.u.; this relative scale will be used hereafter. Analyses were carried out at a pressure in the TOF analyzer of $10^{-4} \mathrm{~Pa}$ and positive or negative ion spectra were recorded in linear and reflectron modes. Mass spectrometric analysis was performed using at least 100 shots and the data obtained were accumulated. Red phosphorus was used for external calibration in both ionization modes. ${ }^{[40]}$ For mass spectrometry, the glasses were crushed in an agate ball mill. About $1 \mathrm{mg}$ of fine powdered glass was suspended in $1 \mathrm{ml}$ of toluene; $1 \mu \mathrm{l}$ of this suspension was deposited on the target sample plate and dried at room temperature in a stream of air. Before the deposition of the samples, the target plate was always cleaned carefully with ethanol, acetone, and deionized water. Desiccated red phosphorus $(\sim 0.1 \mathrm{mg})$ was suspended in $100 \mu \mathrm{L}$ of acetonitrile and $1 \mu \mathrm{l}$ of 
the suspension was deposited on the target plate and used for the analysis. Samples were measured from Parafilm in order to avoid contamination by other elements coming directly from the target during the plasma processes. Parafilm was used as a support material as it can provide good sensitivity, mass resolution, and ion current stability. ${ }^{[41]}$ The target was covered with a small layer of Parafilm $(\sim 0.5 \times 0.5 \mathrm{~cm})$ and each sample was deposited on the target at a distance of $\sim 2 \mathrm{~cm}$ from the other samples in order to avoid contamination.

\section{Software and computation}

Theoretical isotopic envelopes were calculated using Launchpad software (Kompact Version 2.3.4, 2003) from Kratos Analytical Ltd. (Manchester, UK).

\section{RESULTS AND DISCUSSION}

\section{Chemical composition and amorphous state of prepared samples}

EDX analysis shows that the chemical composition of prepared samples is in very good agreement with the nominal composition taking into account error limit of the used EDX method ( \pm 0.5 at.\%). However, the concentration of erbium is too low to be analyzed by EDX. The expected variation of absorption coefficient versus concentration of erbium was checked by optical transmission measurements confirming the theoretical concentration of $\mathrm{Er}^{3+}$ ions in the glass target. The amorphous state and homogeneity of the samples were confirmed by optical/electron microscopy and XRD patterns.

\section{Elucidation of Ga-Ge-Sb-S glasses structure featuring Raman scattering spectra analysis}

The physical properties of chalcogenide glasses are generally discussed - without any consideration on the species - considering the average coordination number of the elements. In the constraints model, a specific value of $\mathrm{m}=2.67$ was attributed to a structural phase transition from a two-dimensional (2D) layered structure to a three-dimensional (3D) network. ${ }^{[42]}$ In $\mathrm{Ga}_{5} \mathrm{Ge}_{20} \mathrm{Sb}_{10} \mathrm{~S}_{65}$ glassy alloy and in the glasses with close chemical composition, the average coordination number (m) was evaluated using the standard procedure described elsewhere and revealed a structure certainly really close to a model of a three-dimensional amorphous network. [43]

In Ga-Ge-Sb-S glasses, the gallium and germanium coordination number is usually assumed to be four as it has been proposed for Ga-Ge-S or $\mathrm{Ga}_{2} \mathrm{~S}_{3}-\mathrm{GeS}_{2}$ based glasses. ${ }^{[44,45]}$ For the $\alpha$ $\mathrm{Ga}_{2} \mathrm{~S}_{3}$ crystal, the fourth bond is a dative bond with a sulphur lone pair and thus a part of the sulphur atoms should be three-fold coordinated. Nevertheless, such a structural organization could be expected in non stoichiometric glasses but it has not been experimentally demonstrated up to now. Instead, it is usually proposed the formation of homopolar bonds like $\left(\mathrm{S}_{3-\mathrm{x}} \mathrm{Ge}_{\mathrm{x}}\right) \mathrm{Ge}-$ $\mathrm{Ge}\left(\mathrm{S}_{3-\mathrm{x}} \mathrm{Ge}_{\mathrm{x}}\right)$ or involving $\mathrm{Ga}$ atoms to overcome the deficit in sulphur. ${ }^{[46]}$

The Raman spectra of Ga-Ge-(Sb)-S glasses (Figure $1 \mathrm{~A}$ ) are dominated by the presence of the band peaking at $\sim 330-340 \mathrm{~cm}^{-1}$, related to the $v_{1}$ symmetric stretching modes of $\left[\mathrm{GeS}_{4 / 2}\right]$ tetrahedral. ${ }^{[4,47]}$ The bands related to the $3 \mathrm{D}$ structure of the glassy network can also be observed; the band (shoulder) at $\sim 370 \mathrm{~cm}^{-1}$ is associated to the $v^{\mathrm{c}}{ }_{1}\left(\mathrm{~A}^{\mathrm{c}}{ }_{1}\right)$ "companion" mode of the $v_{1}$ mode, linked to the vibrations of tetrahedra bound by their edges. The band located at $\sim 430$ $\mathrm{cm}^{-1}$ is assigned with the vibrations of $\mathrm{S}_{3} \mathrm{Ge}-\mathrm{S}-\mathrm{GeS}_{3}$ structural units where tetrahedra are connected by their corners. The presence of a weak Raman band at $\sim 470-480 \mathrm{~cm}^{-1}$, corresponding to the vibrations of S-S bonds, is obviously observed in $\mathrm{Ge}_{25} \mathrm{Ga}_{5} \mathrm{~S}_{70}$ and $\mathrm{Ga}_{5} \mathrm{Ge}_{15} \mathrm{Sb}_{10} \mathrm{~S}_{70}$ glass with a clear excess (over stoichiometry) of sulphur for both of them. ${ }^{[48]}$ At the low wavenumbers side, the shoulder at $\sim 290-300 \mathrm{~cm}^{-1}$ is attributed to the symmetric 
stretching vibration modes of $\left[\mathrm{SbS}_{3 / 2}\right]$ pyramids. Comparing $\mathrm{Ga}_{1} \mathrm{Ge}_{24} \mathrm{Sb}_{10} \mathrm{~S}_{65}$ with $\mathrm{Ga}_{8} \mathrm{Ge}_{17} \mathrm{Sb}_{10} \mathrm{~S}_{65}$, the location of symmetric stretching modes of $\left[\mathrm{GaS}_{4 / 2}\right]$ tetrahedra can be assumed to be around $320 \mathrm{~cm}^{-1}$. In the case of $\mathrm{Ga}_{5} \mathrm{Ge}_{20} \mathrm{Sb}_{10} \mathrm{~S}_{65}$ glass, a weak band around 250$260 \mathrm{~cm}^{-1}$ is assumed to be partially covered by the shoulder previously described. That band is generally associated with the stretching vibrations of the Ge-Ge homopolar bonds in the $\mathrm{S}_{3} \mathrm{Ge}(\mathrm{Ga})-\mathrm{Ge}(\mathrm{Ga}) \mathrm{S}_{3}$ units ${ }^{[49]}$ clearly observed in the spectrum of $\mathrm{Ga}_{3} \mathrm{Ge}_{25} \mathrm{Sb}_{12} \mathrm{~S}_{60}$ glass. Typically, the spectra of S-deficient glasses show some Raman features in the range of 150-250 $\mathrm{cm}^{-1}$, related to the formation of homopolar bonds. Thus, the three bands at $\sim 160,210$ and 260 $\mathrm{cm}^{-1}$ can be connected with vibrations of Sb-Sb homopolar bonds, $\left(\mathrm{S}_{3-\mathrm{x}} \mathrm{Ge} \mathrm{x}_{\mathrm{x}}\right) \mathrm{Ge}-\mathrm{Ge}\left(\mathrm{S}_{3-\mathrm{x}} \mathrm{Ge}_{\mathrm{x}}\right)$ $(\mathrm{x}>0)$ or $\mathrm{Ge}-\mathrm{Sb}$ dissimilar bond and $\mathrm{S}_{3} \mathrm{Ge}(\mathrm{Ga})-\mathrm{Ge}(\mathrm{Ga}) \mathrm{S}_{3}$ units, respectively. ${ }^{[28]}$

In case of $\mathrm{Ga}_{5} \mathrm{Ge}_{20} \mathrm{Sb}_{10} \mathrm{~S}_{65}$ glass (based on Raman data analysis), the glass local structure can be described as a 3D network linking $\left[\mathrm{SbS}_{3 / 2}\right],\left[\mathrm{GaS}_{4 / 2}\right]$, and $\left[\mathrm{GeS}_{4 / 2}\right]$ entities by corners (edges). The presence of $\mathrm{S}-\mathrm{S}$ bonds suggests the formation of $\mathrm{S}_{3} \mathrm{Ge}(\mathrm{Ga})-\mathrm{Ge}(\mathrm{Ga}) \mathrm{S}_{3}$ "wrong" bonds although the presence of three fold coordinated $\mathrm{Ga}$ is not excluded.

\section{Effect of erbium on properties of Ga-Ge-Sb-S glasses}

In the chalcogenide glassy matrix, the rare earth ions seem to be surrounded by 6 or 7 sulphur atoms, ${ }^{[50-52]}$ incorporated on sites close to the gallium atoms in order to balance the partial negative charge of tetrahedral $\left[\mathrm{GaS}_{4}\right]$ units. ${ }^{[53]}$ The introduction of $\mathrm{Ga}$ in Ge-As-S glasses greatly enhanced rare earth solubility and dispersal, particularly for Ga : rare earth ratios $\geq 10: 1$. ${ }^{[54]}$ Note that the study on glasses doped with erbium sulphide suggests that the $\mathrm{Er}^{3+}$ ion occupies only one type of sites in the glassy matrix. ${ }^{[55]}$ In $\mathrm{Ga}_{5} \mathrm{Ge}_{20} \mathrm{Sb}_{10} \mathrm{~S}_{65}$ glass, our EXAFS results suggest that the $\mathrm{Er}^{3+}$ is surrounded by $\sim 7.0 \pm 0.5$ sulphur atoms with bond lengths of $\sim 2.8 \AA$ for a concentration of 1 wt. \% of Er (Figure $1 \mathrm{~B}$ ).

The dopant ( $\mathrm{Er}^{3+}$ ions) has no observable effect on the local structure of the studied Ga-GeSb-S glasses as shown by Raman scattering spectroscopy; this is caused by the low content of dopant (1.0 wt. \% of $\mathrm{Er}^{3+}$ ions at maximum) in the glasses. On the contrary, the presence of $\mathrm{Er}^{3+}$ ions leads to specific features of Ga-Ge-Sb-S glasses regarding their optical properties: i) absorption bands due to ${ }^{4} \mathrm{I}_{15 / 2} \rightarrow{ }^{4} \mathrm{I}_{13 / 2},{ }^{4} \mathrm{I}_{15 / 2} \rightarrow{ }^{4} \mathrm{I}_{11 / 2},{ }^{4} \mathrm{I}_{15 / 2} \rightarrow{ }^{4} \mathrm{I}_{9 / 2}$, and ${ }^{4} \mathrm{I}_{15 / 2} \rightarrow{ }^{4} \mathrm{~F}_{9 / 2}$ intra-f electron transitions of $\mathrm{Er}^{3+}$ ions at $~ 1530,990,810$, and $660 \mathrm{~nm}$ are observed in their transmission spectra, ii) radiative emissions due to ${ }^{4} \mathrm{I}_{9 / 2} \rightarrow{ }^{4} \mathrm{I}_{11 / 2},{ }^{4} \mathrm{I}_{9 / 2} \rightarrow{ }^{4} \mathrm{I}_{13 / 2},{ }^{4} \mathrm{I}_{13 / 2} \rightarrow{ }^{4} \mathrm{I}_{15 / 2},{ }^{4} \mathrm{I}_{11 / 2}$ $\rightarrow{ }^{4} \mathrm{I}_{15 / 2}$, and ${ }^{4} \mathrm{I}_{9 / 2} \rightarrow{ }^{4} \mathrm{I}_{15 / 2}$ transitions are identified at $\sim 4500,1720,1550,900$, and $810 \mathrm{~nm}$ in the photoluminescence spectra. ${ }^{[20]}$ The spectroscopic properties are generally affected when rare earth ions concentration increases. In the case of erbium, several mechanisms of non-radiative relaxation of the excited levels were identified. The energy transfer is a cooperative effect in which an ion gives its energy to a nearest neighbor, at a probability rate that depends on the distance between these ions. Indeed, energy transfers (cross-relaxation, up-conversion mechanisms) take place between rare earth ions and affect both the emission intensities and the lifetimes of excited levels. Besides the effect of the concentration of rare earth, the nature of the host matrix favouring or not the dispersion of the rare earth will influence such mechanisms based on dipole-dipole interactions. For high rare earth ions concentration or their weak dispersion, the chalcogenide glasses can present poor fluorescence efficiency due to critical rare earth ions clustering. It is therefore important to have an idea of the nature of the motifs surrounding the rare earth and not just having a picture of the first coordination sphere identifiable by EXAFS, which may change with the concentration of rare earth.

\section{Mass spectrometry}

Powders of $\mathrm{Ga}_{5} \mathrm{Ge}_{20} \mathrm{Sb}_{10} \mathrm{~S}_{65}$ glass doped with different levels of erbium (0.05, 0.1, and 0.5 wt. \%) were deposited on a target. Mass spectra in positive as well as negative ion modes were recorded 
and analyzed with the aim to determine stoichiometry of singly charged positive and negative $\mathrm{Ga}_{m} \mathrm{Ge}_{n} \mathrm{Sb}_{o} \mathrm{~S}_{p}$ cluster ions generated. The threshold laser energy was found to be almost the same in positive and negative ion mode, at $\sim 50$ a.u. Mass spectra with average value of mass resolution equal to $1000-2500$ and intensity $(>25 \mathrm{mV})$ were observed at laser energies in the interval 70-130 a.u. in positive and 70-160 a.u. in negative ion modes. The clusters generated were observed in mass spectra up to $m / z^{\sim} 1050$ in positive ion and up to $m / z^{\prime} 1010$ values in negative ion mode. The mass spectra were analyzed via comparison of experimental isotopic envelopes with the theoretical models; in this way the stoichiometry of the clusters was determined.

\section{Capacity of mass spectrometer to differentiate Ga from Ge atoms}

Atomic mass of Ga (69.9) and Ge (72.6) is comparatively close but their isotopic patterns are different. Gallium possesses two and germanium possesses five isotopes. At low $\mathrm{m} / \mathrm{z}$, theoretical model shows the congruent cluster pattern between gallium and germanium isotopes but at high $m / z$, cluster patterns of germanium and gallium are separated from each other. An analysis of experimental mass spectra does not show Ga-Ge species, though Ga and Ge were identified in species together with $\mathrm{S}$ and $\mathrm{Sb}$ in both ion modes. Concluding, Ga-Ge bond may not exist in GaGe-Sb-S species and both elements $(\mathrm{Ga}, \mathrm{Ge})$ form only bonds with sulphur or antimony atoms. In spite of the fact that individual elements ( $\mathrm{Ga}, \mathrm{Ge}, \mathrm{Sb}, \mathrm{S}$, and Er) are showing a number of isotopes (2, 5, 2, 3, and 6) and thus corresponding isotopic envelopes of $\mathrm{Ga}_{m} \mathrm{Ge}_{n} \mathrm{Sb}_{o} \mathrm{~S}_{p}$ clusters are quite different, there are some difficulties. For example, ${ }^{70} \mathrm{Ge},{ }^{72} \mathrm{Ge}$ and ${ }^{71} \mathrm{Ga}_{2}$ clusters are based on almost identical masses (141.84 and 141.86). This makes the clusters identification difficult.

\section{Effect of laser energy}

The effect of laser energy on the mass spectra of all the glasses was followed. As an example, the mass spectra of $\mathrm{Ga}_{5} \mathrm{Ge}_{20} \mathrm{Sb}_{10} \mathrm{~S}_{65}$ glass doped with erbium (0.05 wt. \%) at different laser energies are shown in Figure 2 A. It was observed that at lower laser energy (90 a.u.), $\mathrm{Ga}_{m} \mathrm{Ge}_{n} \mathrm{Sb}_{o} \mathrm{~S}_{p}$ clusters were disappearing. Increasing the laser energy, the intensity of the peaks increases but the resolution of the mass spectra falls down at laser energies of 150 a.u. and higher. The laser energy effect for the highest concentration (0.5 wt. \%) of $\mathrm{Er}^{3+}$ ions in $\mathrm{Ga}_{5} \mathrm{Ge}_{20} \mathrm{Sb}_{10} \mathrm{~S}_{65}$ glass is shown in Figure $2 \mathrm{~B}$. Formation and proliferation of peaks are observed from lower to higher mass range with increasing laser energy. Several peaks were observed at laser energy of 90 a.u. in higher mass range (800-1000) whilst such peaks were not observed at lower laser energy. In Ga-Ge-Sb-S plasma, species in lower mass range 1-800 ionize at laser energy of 50-70 a.u. and within higher mass range (800-1050) sufficient peaks intensity and resolution were achieved at 90 a.u.

\section{Positive ion mode}

The mass spectra for three $\mathrm{Ga}_{5} \mathrm{Ge}_{20} \mathrm{Sb}_{10} \mathrm{~S}_{65}$ glass samples with different levels of erbium (0.05, 0.1, 0.5 wt. \%) were measured and analyzed. The results concerning all the samples show a great degree of similarity. Examples of mass spectra for 0.1 wt. \% $\mathrm{Er}^{3+}$ doped $\mathrm{Ga}_{5} \mathrm{Ge}_{20} \mathrm{Sb}_{10} \mathrm{~S}_{65}$ glass forming plasma at laser energy of 90 a.u. are shown in Figures $3 \mathrm{~A}$, B. The stoichiometries of the $\mathrm{Ga}_{m} \mathrm{Ge}_{n} \mathrm{Sb}_{o} \mathrm{~S}_{p}^{+/-}$clusters were determined via isotopic envelope analysis and computer modelling. In spite of the fact that germanium content in glasses is four times higher than the content of gallium, for all the glasses, $\mathrm{Ga}^{+}$ion was observed to be the main species in the plasma and $\mathrm{Sb}_{3} \mathrm{~S}^{+}$ as the second one most intensive. Mass spectra in positive ion mode show low number of Ge- 
based clusters. The reason can be difficulty in the ionization of germanium into positively single charged ions. Nine series of clusters, $\mathrm{Ga}_{m} \mathrm{~S}_{p}^{+}(m=3, p=1,2), \mathrm{Sb}_{o} \mathrm{~S}_{p}^{+}(o=3, p=1-4), \mathrm{Ga}_{m} \mathrm{Sb}_{o} \mathrm{~S}_{p}{ }^{+}$ $(m=1, o=1, p=1,2), \mathrm{Ga}_{m} \mathrm{Sb}_{o} \mathrm{~S}_{p}^{+}(m=2, o=1, p=2,3), \mathrm{Ga}_{m} \mathrm{Sb}_{o} \mathrm{~S}_{p}^{+}(m=1, o=2, p=2-5)$, $\mathrm{Ga}_{m} \mathrm{Sb}_{o} \mathrm{~S}_{p}^{+}(m=2, o=2, p=4,5), \mathrm{Ga}_{m} \mathrm{Sb}_{o} \mathrm{~S}_{p}^{+}(m=3, o=2, p=4-7), \mathrm{Ga}_{m} \mathrm{Sb}_{o} \mathrm{~S}_{p}^{+}(m=2, o=3, p$ = 5-7), and $\mathrm{Ga}_{m} \mathrm{Sb}_{o} \mathrm{~S}_{p}{ }^{+}(m=1, o=4, p=6,7)$ were identified. Six species were found to overlap with another one: $\mathrm{GaSbS}^{+}$with $\mathrm{GaSbSH}^{+}$( 30\%), $\mathrm{GaSb}_{2} \mathrm{~S}_{5}^{+}$with $\mathrm{Ga}_{5} \mathrm{~S}_{4}{ }^{+}(\sim 80 \%), \mathrm{ErGaSb}_{2} \mathrm{~S}^{+}$ with $\mathrm{Ga}_{2} \mathrm{Sb}_{2} \mathrm{~S}_{4}^{+}$( 20\%), $\mathrm{Ga}_{4} \mathrm{SbS}_{5}^{+}$with $\mathrm{GaSb}_{3} \mathrm{~S}_{4}{ }^{+}(\sim 60 \%), \mathrm{Ga}_{3} \mathrm{GeSb}_{2} \mathrm{~S}_{3} \mathrm{H}_{4}{ }^{+}$with $\mathrm{Ga}_{8} \mathrm{GeH}_{3}{ }^{+}$ ( 20\%), and $\mathrm{Ga}_{2} \mathrm{Sb}_{3} \mathrm{~S}_{5}{ }^{+}$with $\mathrm{Ga}_{5} \mathrm{SbS}_{6} \mathrm{H}^{+}$(40\%). In the mass rage up to $\mathrm{m} / \mathrm{z} 300$, unary $\mathrm{Ga}^{+}$and binary $\mathrm{Ga}_{m} \mathrm{~S}_{p}{ }^{+}(m=3, p=1,2)$ species were found to be the most abundant. The intensities of the peaks corresponding to two $\mathrm{Sb}_{o} \mathrm{~S}_{p}{ }^{+}$species with 1:1 elemental proportions were found to be almost the same. Binary $\mathrm{Sb}_{o} \mathrm{~S}_{p}{ }^{+}(o=3, p=1-4)$ species with odd number of sulphur atoms were identified as more abundant than the clusters with even number of sulphur atoms. At lower mass range, $\mathrm{GaSbS}^{+}$and $\mathrm{GaGeS}^{+}$species with almost the same peak intensities were detected. Species of $\mathrm{Ga}_{m} \mathrm{Sb}_{n} \mathrm{~S}_{o}^{+}$series were found with decreasing peak intensities when increasing number of sulphur atoms. The species of $\mathrm{Ga}_{m} \mathrm{Sb}_{o} \mathrm{~S}_{p}{ }^{+}(m=2, o=1, p=2-4)$ series were showing increasing intensity of peaks when increasing number of sulphur atoms. The intensities of $\mathrm{Ga}_{m} \mathrm{Sb}_{o} \mathrm{~S}_{p}^{+}(m=$ $1, o=2, p=2-5$ ) species were higher for $p=2$ or 4 than for clusters with $p=3$ or 5 . Species $\mathrm{Ga}_{m} \mathrm{Sb}_{o} \mathrm{~S}_{p}{ }^{+}(m=1, o=2, p=2-5)$ with odd number of sulphur atoms are more abundant than those with even numbers. At higher mass range (500-1050 m/z), the species $\mathrm{Ga}_{3} \mathrm{Sb}_{2} \mathrm{~S}_{7}^{+}$was detected as the main one (Figure $3 \mathrm{~B}$ ). Interestingly, two clusters with 4 and 5 sulphur atoms, $\mathrm{Ga}_{m} \mathrm{Sb}_{o} \mathrm{~S}_{p}{ }^{+}(m=3, o=2, p=4,5)$, with similar peak intensities were identified. The abundance of $\mathrm{Ga}_{m} \mathrm{Sb}_{o} \mathrm{~S}_{p}^{+}(m=2, o=3, p=6,7)$ species is almost the same. Clusters $\mathrm{Ga}_{3} \mathrm{GeS}_{15}{ }^{+}$and $\mathrm{Ga}_{4} \mathrm{SbS}_{16}{ }^{+}$, rich in sulphur, were detected at high $\mathrm{m} / \mathrm{z}$. Some selected parts of experimental mass spectra measured for $\mathrm{Ga}_{5} \mathrm{Ge}_{20} \mathrm{Sb}_{10} \mathrm{~S}_{65}$ glass doped with $0.1 \mathrm{wt}$. \% of erbium and their comparison with theoretical model are shown in Figure 4.

It is important to note that even if $\mathrm{Ga}_{5} \mathrm{Ge}_{20} \mathrm{Sb}_{10} \mathrm{~S}_{65}$ glass was doped with different Er levels (0.05, $0.1,0.5$ wt. \%), mass spectra of all the samples show only two erbium containing species; these are $\mathrm{GaSb}_{2} \mathrm{SEr}^{+}$and $\mathrm{GaS}_{6} \mathrm{Er}_{2}{ }^{+}$at high mass range and none at low mass range. High number of ternary $\mathrm{Ga}_{m} \mathrm{Sb}_{o} \mathrm{~S}_{p}{ }^{+}$species was identified; only two species $\left(\mathrm{Ga}_{2} \mathrm{GeSbS}_{6}{ }^{+}\right.$and $\left.\mathrm{Ga}_{3} \mathrm{GeSb}_{2} \mathrm{~S}_{3} \mathrm{H}_{4}{ }^{+}\right)$ were containing all elements (Ga, Ge, Sb and S). Few peaks at lower (80-160) and higher (8001050) mass range were not identified. For a clarity, a summary of positively charged $\mathrm{Ga}_{m} \mathrm{Ge}_{n} \mathrm{Sb}_{o} \mathrm{~S}_{p}^{+}$species identified in mass spectra of plasma formed from erbium doped Ga-GeSb-S glasses is given in Table 1.

\section{Negative ion mode}

In comparison with the positive ion mode, LDI-TOF mass spectra measured in linear and/or reflectron negative ion modes lead to the generation of a slightly higher number of clusters. The mass spectra were measured and analysed for three samples (all erbium levels). An example of mass spectra measured from 0.5 wt. \% of Er doped $\mathrm{Ga}_{5} \mathrm{Ge}_{20} \mathrm{Sb}_{10} \mathrm{~S}_{65}$ glass at laser energy of 80 a.u. is shown in Figure 5 A, B. The stoichiometry of the $\mathrm{Ga}_{m} \mathrm{Ge}_{n} \mathrm{Sb}_{o} \mathrm{~S}_{p}^{+/-}$clusters was again determined via isotopic envelope analysis and computer modelling. For all the glasses, $\mathrm{GaS}_{2}$ species was found to be the main cluster and $\mathrm{SbS}_{2}{ }_{2}$ the second most abundant. Among Ge-based species, $\mathrm{GaGeS}_{4}{ }^{-}$is the third most abundant species detected in negative ion mode. The formation of this species, congruent to $\left[\mathrm{Ge}(\mathrm{Ga}) \mathrm{S}_{4 / 2}\right.$ ] entities identified in the Raman spectra of Ga-Ge-Sb-S glasses, is showing that Ge is mostly coordinated with four sulphur atoms. High intensity of $\mathrm{GaS}_{2}{ }^{-}$and $\mathrm{SbS}_{2}{ }^{-}$is probably due to easier ionization. Fifteen series of clusters, $\mathrm{S}_{p}{ }^{-}(p$ $=1-3), \mathrm{Sb}_{o} \mathrm{~S}_{p}^{-}(o=1, p=1-3), \mathrm{Ga}_{m} \mathrm{~S}_{p}^{-}(m=1, p=2,3), \mathrm{Ga}_{m} \mathrm{~S}_{p}^{-}(m=3, p=3,4), \mathrm{Ga}_{m} \mathrm{Sb}_{o}^{-}(m=4,5$, $o=2), \mathrm{Ge}_{n} \mathrm{Sb}_{o} \mathrm{~S}_{p}^{-}(n=1, o=1, p=3-5), \mathrm{Ga}_{m} \mathrm{Ge}_{n} \mathrm{~S}_{p}(m=1, n=1, p=3-5), \mathrm{Sb}_{o} \mathrm{~S}_{p}^{-}(o=3, p=$ 4,5), $\mathrm{Ga}_{m} \mathrm{Ge}_{n} \mathrm{Sb}_{o} \mathrm{~S}_{p}{ }^{-}(m=1, n=1, o=1, p=4,5), \mathrm{Ga}_{m} \mathrm{Sb}_{o} \mathrm{~S}_{p}^{-}(m=2, o=1, p=4,5), \mathrm{Ga}_{m} \mathrm{Sb}_{o} \mathrm{~S}_{p}(m$ $=1, o=2, p=4-6), \mathrm{Ga}_{m} \mathrm{Sb}_{o} \mathrm{~S}_{p}(m=1, o=3, p=5,6), \mathrm{Ga}_{m} \mathrm{Sb}_{o} \mathrm{~S}_{p}^{-}(m=2, o=2, p=6,7)$, 
$\mathrm{Ga}_{m} \mathrm{Sb}_{o} \mathrm{~S}_{p}{ }^{-}(m=3, o=2, p=7,8)$, and $\mathrm{Ga}_{m} \mathrm{Sb}_{o} \mathrm{~S}_{p}{ }^{-}(m=5, o=2, p=10,11)$ were identified. Fourteen of the species identified were found to overlap with another one: $\mathrm{GaSbS}_{3}{ }^{-}$with $\mathrm{GeSbS}_{3}{ }_{-}$ ( $60 \%), \mathrm{Ga}_{3} \mathrm{~S}_{3}{ }_{3}$ with $\mathrm{GaGeS}_{5}^{-}$( $\left.70 \%\right), \mathrm{Sb}_{2} \mathrm{~S}_{3}^{-}$with $\mathrm{Ga}_{3} \mathrm{~S}_{4}^{-}$( $\left.90 \%\right), \mathrm{Ga}_{2} \mathrm{SbS}_{4}^{-}$with $\mathrm{GaGeSbS}_{4}^{-}$ ( $50 \%), \mathrm{Ga}_{2} \mathrm{SbS}_{5}^{-}$with $\mathrm{GaGeSbS}_{5}{ }^{-}$( $\left.40 \%\right), \mathrm{Ga}_{3} \mathrm{GeS}_{7}^{-}$with $\mathrm{GaSb}_{2} \mathrm{~S}_{6}{ }^{-}$( $\left.40 \%\right), \mathrm{Sb}_{3} \mathrm{~S}_{5}{ }_{-}^{-}$ withGa $\mathrm{Sb}_{2}{ }^{-}$( $\left.30 \%\right), \mathrm{Ga}_{2} \mathrm{GeSb}_{3}{ }^{-}$with $\mathrm{Ga}_{2} \mathrm{Sb}_{2} \mathrm{~S}_{6}{ }^{-}$( $\left.75 \%\right), \mathrm{GaSb}_{3} \mathrm{~S}_{5}{ }^{-}$with $\mathrm{Ga}_{5} \mathrm{Sb}_{2}{ }^{-}$( $\left.90 \%\right), \mathrm{Sb}_{5}$ with $\mathrm{Ga}_{2} \mathrm{Sb}_{2} \mathrm{~S}_{7}^{-}$( $\left.20 \%\right), \mathrm{Ga}_{5} \mathrm{Sb}_{2} \mathrm{SH}_{2}{ }^{-}$with $\mathrm{GaSb}_{3} \mathrm{~S}_{6}{ }^{-}$( $\left.70 \%\right), \mathrm{Ga}_{5} \mathrm{~S}_{16}{ }^{-}$with $\mathrm{Ga}_{4} \mathrm{Sb}_{4} \mathrm{~S}_{3}{ }^{-}$( $\left.50 \%\right)$, $\mathrm{GaGeS}_{4}$ with $\mathrm{Ga}_{2} \mathrm{~S}_{4} \mathrm{H}^{-}(\sim 40 \%)$, and $\mathrm{Ge}_{3} \mathrm{SH}_{3}{ }^{-}$with $\mathrm{SbS}_{4} \mathrm{H}_{4}{ }^{-}(\sim 25 \%)$. Concerning $\mathrm{Ga}_{m} \mathrm{~S}_{p}^{-}(m=1$, $p=2,3)$ and $\mathrm{Sb}_{n} \mathrm{~S}_{o}{ }^{-}(n=1, o=1-3)$ species, highest peak intensities were observed for $\mathrm{GaS}_{2}{ }^{-}$and $\mathrm{SbS}_{2}{ }^{-}$species. Thus, we can speculate that such clusters might be considered as a part of the structural network of Ga-Ge-Sb-S glasses. Concerning $\mathrm{Ga}_{m} \mathrm{Ge}_{n} \mathrm{~S}_{p}{ }^{-}(m=1, n=1, p=3-5)$ series, the species $\mathrm{GaGeS}_{4}{ }^{-}$is the main one. Only one series $\mathrm{Ga}_{m} \mathrm{Ge}_{n} \mathrm{Sb}_{o} \mathrm{~S}_{p}{ }^{-}(m=1, n=1, o=1, p=4,5)$ containing all the elements of Ga-Ge-Sb-S glass was identified. At lower mass rage (up to 500 $\mathrm{m} / \mathrm{z}$ ), species $\mathrm{Ge}_{3} \mathrm{SbS}^{-}, \mathrm{Sb}_{3} \mathrm{~S}_{4}{ }^{-}, \mathrm{Ga}_{5} \mathrm{GeSH}_{2}{ }^{-}$and three species $\left(\mathrm{GeSbS}_{5}{ }^{-}, \mathrm{Ga}_{2} \mathrm{SbS}_{5}{ }^{-}, \mathrm{GaSb}_{2} \mathrm{~S}_{5}{ }^{-}\right)$with maximum of five atoms of sulphur were identified. Up to $\mathrm{m} / \mathrm{z} 220$ mass, unary (only sulphur) and binary (only gallium and antimony sulphides) clusters were identified. We can suggest that ionization and formation of unary clusters of sulphur and binary clusters of gallium-sulphur and antimony-sulphur at lower $\mathrm{m} / \mathrm{z}$ are favourable (up to $\mathrm{m} / \mathrm{z} 220$ ) than the formation of ternary clusters while the formation of few binary gallium-sulphur and antimony-sulphur clusters was also observed. Mass spectrum in the mass range $500-1010 \mathrm{~m} / \mathrm{z}$ is presented in Figure $5 \mathrm{~B}$. Here, species $\mathrm{Ga}_{3} \mathrm{Sb}_{2} \mathrm{~S}_{8}{ }^{-}$was detected as the main one and $\mathrm{Ga}_{6} \mathrm{Sb}_{2} \mathrm{~S}^{-}$as the second most abundant. The species $\mathrm{Ga}_{3} \mathrm{GeSb}_{2} \mathrm{~S}^{-}, \mathrm{Ga}_{2} \mathrm{Ge}_{3} \mathrm{SbS}_{2}{ }_{-}^{-}$, and $\mathrm{GaGeSb}_{2} \mathrm{~S}_{8}{ }^{-}$(containing all the elements of Ga-Ge-Sb-S glass) were identified. Unary $\mathrm{Sb}_{5}$ cluster was found to be the third most populated species. Four binary species $\mathrm{Ga}_{m} \mathrm{Sb}_{o}{ }^{-}(m=4,5, o=2), \mathrm{Sb}_{3} \mathrm{~S}_{5}{ }^{-}$, and $\mathrm{Ga}_{5} \mathrm{~S}_{16}{ }^{-}$were identified. From total number of 41 ternary species, only $\mathrm{Ga}_{2} \mathrm{Ge}_{2} \mathrm{Sb}$ cluster is free of sulphur. Five germanium containing species were identified. The highest numbers of individual atoms forming negatively charged species were found to be $8,3,6$, and 16 for $\mathrm{Ga}, \mathrm{Ge}, \mathrm{Sb}$, and S, respectively. Selected parts of experimental mass spectra measured for $\mathrm{Ga}_{5} \mathrm{Ge}_{20} \mathrm{Sb}_{10} \mathrm{~S}_{65}$ glass doped with erbium (0.5 wt. \%) and comparison with theoretical model at lower, middle, and higher $m / z$ values among the whole range of experimental mass spectra are shown in Figure 6 A. A summary of negatively charged $\mathrm{Ga}_{m} \mathrm{Ge}_{n} \mathrm{Sb}_{o} \mathrm{~S}_{p}$ species identified in mass spectra coming from $\mathrm{Ga}_{5} \mathrm{Ge}_{20} \mathrm{Sb}_{10} \mathrm{~S}_{65}$ glass doped with $0.05,0.1$, and 0.5 wt. \% of erbium is given in Table 2 .

Four unary, sixteen binary species in negative ion mode and one unary and nine binary species in positive ion mode were detected. No unary sulphur containing species were identified in positive ion mode. Three sulphur species $\mathrm{S}_{p}{ }^{-}(p=1-3)$ and one antimony species $\mathrm{Sb}_{5}{ }_{5}$ were identified in negative ion mode. A review of the species identified in the mass spectra of positive and negative ion modes is given in Table 3. The overlapping of ternary species was found to be more frequent than the overlap of binary species. Two species containing erbium $\left(\mathrm{GaSb}_{2} \mathrm{SEr}^{+}\right.$ and $\mathrm{GaS}_{6} \mathrm{Er}_{2}{ }^{+}$) were identified in positive ion mode, but no erbium containing species were identified in negative ion mode. High number of ternary $\mathrm{Ga}_{m} \mathrm{Sb}_{o} \mathrm{~S}_{p}{ }^{+}$species was found in both ion modes. Even if the cluster ions were generated up to $\mathrm{m} / \mathrm{z} \sim 1000$ in both ion modes, surprisingly we have identified only four species $\mathrm{Sb}_{3} \mathrm{~S}_{4}{ }^{+/-}, \mathrm{Ga}_{m} \mathrm{Sb}_{o} \mathrm{~S}_{p}^{+/-}(m=1, o=2, p=4,5)$, $\mathrm{Ga}_{3} \mathrm{Sb}_{2} \mathrm{~S}_{7}^{+/-}$common to both ion modes. In comparison to a high number of $\mathrm{Ga}_{m} \mathrm{Sb}_{o} \mathrm{~S}_{p}^{+/-}$species, the formation of germanium containing species leads to a low number of clusters. Comparison of some Ge-based clusters with theoretical models is shown in Figure 6 B. Mass spectra in negative ion mode show formation of higher number of Ge-based species (16) than in positive ion mode (5).

\section{Remark concerning hydrogen containing species}

Two germanium based species containing hydrogen were found in positive ion mode. Four $\mathrm{Ga}_{m} \mathrm{Sb}_{o} \mathrm{~S}_{p}{ }^{+}$and one $\mathrm{Ga}_{m} \mathrm{~S}_{p}{ }^{+}$species containing hydrogen were identified in positive ion mode. 
$\mathrm{Ge}_{3} \mathrm{SH}_{3}{ }^{-}, \mathrm{Ga}_{5} \mathrm{GeSH}_{2}{ }^{-}$and $\mathrm{Ga}_{5} \mathrm{Sb}_{2} \mathrm{SH}_{2}{ }^{-}$species were identified in negative ion mode. Detection of some hydrogenated clusters could be explained by hydrogen impurity presence. It is known that hydrogen is one of the main impurities in chalcogenide glasses. ${ }^{[56]}$ In spite of using $99.999 \%$ purity $\mathrm{Ga} / \mathrm{Ge} / \mathrm{Sb} / \mathrm{S}$ elements in this work, the hydrogen impurity could cause a partial formation of hydrogenated species. In principle, the process to vanish hydrogen is mainly focused on sulphur purification. In studied chalcogenide glasses, the content of S:H can vary from 15 to 700 ppm (depending on the level of purification) which can affect strongly the quantum efficiency of radiative transitions (luminescence) of erbium ions. ${ }^{[20]}$ As the detection limit of TOF MS is up to femtomole, traces of hydrogen containing species were observable. It should be noted that spectra were also acquired in reflectron ion mode but no significant differences were observed between both ion modes.

\section{LDI-TOF MS results versus Raman data}

Some structural studies of Ga-Ge-Sb-S glasses employing Raman spectroscopy, EXAFS or EPR have been already reported in the literature as we discussed above. However, as far as we know, mass spectrometry study of Ga-Ge-Sb-S glasses is not reported yet.

In this work, it was observed that many singly charged clusters are present in plasma plume generated from $\mathrm{Ga}_{5} \mathrm{Ge}_{20} \mathrm{Sb}_{10} \mathrm{~S}_{65}$ glasses doped with erbium. As discussed above based on Raman scattering spectroscopy results, 3D glassy network contains $\mathrm{GeS}_{4}, \mathrm{GaS}_{4}$, and $\mathrm{SbS}_{3}$ structural units. LDI-TOF MS results might evidence at least some of them. For example, the species $\mathrm{GaSb}_{2} \mathrm{~S}_{4}{ }^{+-}$can be formulated as $\mathrm{Sb}_{2}\left[\mathrm{GaS}_{4}\right]^{+/}$with $\mathrm{GaS}_{4}$ tetrahedral group. Further, also the species $\mathrm{Ga}\left[\mathrm{GeS}_{4}\right]^{-}$and $\mathrm{SbS}_{3}{ }^{-}$detected in negative ion mode are congruent to $\mathrm{GeS}_{4}$ tetrahedral group and $\mathrm{SbS}_{3}$ units, respectively. We suggest that sulphur containing species, for example $\mathrm{S}^{-}$, $\mathrm{S}_{2}{ }^{-}, \mathrm{S}_{3}{ }^{-}, \mathrm{GaS}_{2}$, and $\mathrm{GaS}_{3}{ }^{-}$generated in plasma plume can be part of original 3D glass structure which is probably destroyed by the high energy laser pulses. In higher mass range (500-700 m/z) as the third intensive peak $\mathrm{Ga}_{2} \mathrm{Sb}_{2} \mathrm{~S}_{7}{ }^{-}$species was identified. Interestingly, this specific entity was reported for organometallic compounds in the paper of Feng et al. ${ }^{[57]}$ where the authors suggest that $\left[\mathrm{Ga}_{2} \mathrm{Sb}_{2} \mathrm{~S}_{7}\right] \mathrm{S}_{2}{ }^{-}$unit is consisting of two $\mathrm{GaS}_{4}$ tetrahedra and two $\mathrm{SbS}_{3}$ trigonal pyramids. They form heterometallic cluster in which two $\mathrm{Ga}_{2} \mathrm{SbS}_{3}$ rings are observed. The species $\mathrm{Ga}_{2} \mathrm{SbS}_{3}{ }^{+}$was also detected in positive ion mode. Consequently, structural elements of species $\mathrm{Ga}_{2} \mathrm{Sb}_{2} \mathrm{~S}_{7}{ }^{-}, \mathrm{SbS}_{3}{ }^{-},\left[\mathrm{GaS}_{4}\right] \mathrm{Ge}^{-}$, and $\mathrm{Ga}_{2} \mathrm{SbS}_{3}{ }^{+}$identified in mass spectra may participate in the building of the Ga-Ge-Sb-S glass network and are not in contradiction with results obtained by Raman spectroscopy where vibrational modes of $\mathrm{Ga}(\mathrm{Ge}) \mathrm{S}_{4}$ and $\mathrm{SbS}_{3}$ entities were observed.

In the literature, there is no clear information about the contribution of erbium to sulphide glass structure. According to EXAFS analysis, erbium (within its first coordination sphere) is described in a polyhedron made of 6-7 sulphur atoms. We have identified only two species of erbium, both of them containing gallium atoms $\left(\mathrm{GaSb}_{2} \mathrm{SEr}^{+}\right.$and $\left.\mathrm{GaS}_{6} \mathrm{Er}_{2}{ }^{+}\right)$. This result is in agreement with earlier EPR study where association of rare earth with Ga entities within the glassy network was proposed. The second cluster corresponds to the structural fragment (suggested in the literature for high concentration of erbium) which could be involved in clustering effect. $^{\text {[58] }}$

Structure of clusters formed can resemble to a certain extend the structure of original material. Because the stoichiometry of cluster ions formed was not too much changed when laser fluence was increased, it was therefore assumed (in agreement with the literature) that clusters are at least partially fragments of the original material. There are many papers which show structural characterization of inorganic compounds by LDI and MALDI TOF MS; for example of inorganic coordination complexes, ${ }^{[59]}$ polyester $^{[60]}$ or thiol self-assembled films. ${ }^{[61]}$ Also, LDI and MALDI results of inorganic polymer $\left(\mathrm{P}_{3} \mathrm{~N}_{5}\right)$ show many clusters with similar stoichiometry. ${ }^{[34]}$ Further, LDI analysis of bulk and PLD films of As-S-Se glasses show many clusters with similar stoichiometry. ${ }^{[37]}$ It is clear evidence that LDI/MALDI reflects information 
about structural fragments existing in solids. However, it is difficult to estimate to which extent LDI MS data account on actual structure (prior to desorption) but we are convinced that there is some relation.

\section{CONCLUSIONS}

In this work, laser desorption ionization time-of-flight mass spectrometry was employed for the analysis of plasma formed from multi-component chalcogenide glasses. The mass spectra measured from $\mathrm{Ga}_{5} \mathrm{Ge}_{20} \mathrm{Sb}_{10} \mathrm{~S}_{65}$ glass doped with erbium $(0.05,0.1$, and $0.5 \mathrm{wt} \%$ ) show the formation of nine series of clusters in positive ion mode and fifteen series of clusters in negative ion mode. Slightly higher number of different clusters was detected in the negative ion mode. For all the studied glasses, $\mathrm{Ga}^{+}$ion was found to be the main species and $\mathrm{Sb}_{3} \mathrm{~S}^{+}$was found to be the second main species in positive ion mode. The $\mathrm{GaS}_{2}{ }^{-}$species was identified as the main species and $\mathrm{SbS}_{2}{ }^{-}$the second main species in negative ion mode. Only four species $\mathrm{Sb}_{3} \mathrm{~S}_{4}{ }^{+/}$, $\mathrm{Ga}_{m} \mathrm{Sb}_{o} \mathrm{~S}_{p}^{+/-}(m=1, o=2, p=4,5)$, and $\mathrm{Ga}_{3} \mathrm{Sb}_{2} \mathrm{~S}_{7}{ }^{+/-}$were commonly detected in both positive and negative ion modes. Six species in positive and fourteen species in negative ion modes were identified with the overlap of another species. Only two erbium containing species, $\mathrm{GaSb}_{2} \mathrm{SEr}^{+}$ and $\mathrm{GaS}_{6} \mathrm{Er}_{2}{ }^{+}$, were detected in positive ion mode. This result clearly confirms that erbium and gallium are in chalcogenide glasses associated in specific units which may also involve antimony as nearest neighbor. We speculate that the presence of $\mathrm{GaS}_{6} \mathrm{Er}_{2}{ }^{+}$species can be the reason for erbium ions clustering effect which is parasitic for spectroscopic properties of $\mathrm{Er}^{3+}$ ions in studied glassy matrix. We note that all the mass spectra show lower number of Ge-based clusters than one could expect with respect to the stoichiometry of studied glasses; this fact could be explained by difficult ionization of germanium.

The local structure of (Ga)-Ge-(Sb)-S glasses was studied using Raman scattering spectroscopy; it was revealed that the local structure is formed mainly by $\mathrm{Ge}(\mathrm{Ga}) \mathrm{S}_{4 / 2}$ tetrahedra and $\mathrm{SbS}_{3 / 2}$ pyramids. Some of clusters like $\mathrm{Ga}_{2} \mathrm{Sb}_{2} \mathrm{~S}_{7}{ }^{-}$or $\mathrm{Ga}_{2} \mathrm{SbS}_{3}{ }^{+}$, identified by LDI-TOF MS, could be considered to be structural fragments of the $\mathrm{Ga}_{5} \mathrm{Ge}_{20} \mathrm{Sb}_{10} \mathrm{~S}_{65}$ glass structure. Other species identified in the plasma plume are probably not present in the $\mathrm{Ga}_{5} \mathrm{Ge}_{20} \mathrm{Sb}_{10} \mathrm{~S}_{65}$ glass structure as they can evidently be formed via the interaction of the highly energetic species in the plasma plume. Finally, EXAFS data analysis shows that $\mathrm{Er}^{3+}$ ions in $\mathrm{Ga}_{5} \mathrm{Ge}_{20} \mathrm{Sb}_{10} \mathrm{~S}_{65}$ glasses are surrounded by $\sim 7$ sulphur atoms.

\section{ACKNOWLEDGMENTS}

Support from Czech Science Foundation (Project No. 13-05082S) is greatly acknowledged. This research has been also supported by the project $R \& D$ center for low-cost plasma and nanotechnology surface modifications CZ.1.05/2.1.00/03.0086 funded by European Regional Development Fund. 


\section{REFERENCES}

[1] B. J. Eggleton, B. Luther-Davies, K. Richardson. Chalcogenide photonics. Nat. Photon. 2011, 5, 141.

[2] S. Raoux, W. Welnic, D. Ielmini. Phase change materials and their application to nonvolatile memories. Chem. Rev. 2010, 110, 240.

[3] C. Florea, M. Bashkansky, J. Sanghera, I. Aggarwal, Z. Dutton. Slow-light generation through Brillouin scattering in As2S3 fibers. Opt. Mater. 2009, 32, 358.

[4] S. Maurugeon, B. Bureau, C. Boussard-Pledel, A. J. Faber, P. Lucas, X. H. Zhang, J. Lucas. Selenium modified GeTe4 based glasses optical fibers for far-infrared sensing. Opt. Mater. 2011, 33, 660.

[5] Q. Coulombier, L. Brilland, P. Houizot, T. Chartier, T. N. N'Guyen, F. Smektala, G. Renversez, A. Monteville, D. Mechin, T. Pain, H. Orain, J. C. Sangleboeuf, J. Troles. Casting method for producing low-loss chalcogenide microstructured optical fibers. Opt. Express 2010, 18, 9107.

[6] A. B. Seddon. A Prospective for New Mid-Infrared Medical Endoscopy Using Chalcogenide Glasses. Int. J. Appl. Glass Sci. 2011, 2, 177.

[7] Z. L. Samson, K. F. MacDonald, F. De Angelis, B. Gholipour, K. Knight, C. C. Huang, E. Di Fabrizio, D. W. Hewak, N. I. Zheludev. Metamaterial electro-optic switch of nanoscale thickness. Appl. Phys. Lett. 2010, 96, 143105.

[8] A. Zakery, S. R. Elliott. Optical properties and applications of chalcogenide glasses: a review. J. Non-Cryst. Solids 2003, 330, 1.

[9] D. W. Hewak, J. A. M. Neto, B. Samson, R. S. Brown, K. P. Jedrzejewski, J. Wang, E. Taylor, R. I. Laming, G. Wylangowski, D. N. Payne. Quantum-Efficiency of Praseodymium Doped Galas Glass for 1.3 Mu-M Optical-Fiber Amplifiers. IEEE Photon. Technol. Lett. 1994, 6, 609.

[10] T. Schweizer, D. W. Hewak, B. N. Samson, D. N. Payne. Spectroscopy of Potential MidInfrared Laser Transitions in Gallium Lanthanum Sulphide Glass. J. Lumin. 1997, 72-4, 419.

[11] B. Cole, L. B. Shaw, P. C. Pureza, R. Mossadegh, J. S. Sanghera, I. D. Aggarwal. RareEarth Doped Selenide Glasses and Fibers for Active Applications in the Near and Mid-Ir. J. Non-Cryst. Solids 1999, 257, 253.

[12] B. Cole, L. B. Shaw, P. C. Pureza, R. Miklos, J. S. Sanghera, I. D. Aggarwal. Core/Clad Selenide Glass Fiber Doped With Pr3+ for Active Mid-Ir Applications. J. Mater. Sci. Lett. 2001, 20, 465.

[13] M. F. Churbanov, Scripachev, I. V.,Shiryaev, V. S.,Plotnichenko, V. G., Smetanin, S. V., E. B.Pyrkov, Y. N.Galagan, B. I. . Chalcogenide glasses doped with Tb, Dy and Pr ions. J. Non-Cryst. Solids 2003, 326, 301.

[14] J. Heo. Optical Characteristics of Rare-Earth-Doped Sulfide Glasses. J. Mater. Sci. Lett. 1995, 14, 1014.

[15] L. S. Griscom, J. L. Adam, K. Binnemans. Optical Study of Halide Modified Sulfide Glasses Containing Neodymium Ions. J. Non-Cryst. Solids 1999, 257, 383.

[16] J. Heo. 1.3-mu m-emission properties and local structure of Dy3+ in chalcohalide glasses. C. R. Chimie 2002, 5, 739 .

[17] T. Schweizer, B. N. Samson, J. R. Hector, W. S. Brocklesby, D. W. Hewak, D. N. Payne. Infrared Emission and Ion-Ion Interactions in Thulium- and Terbium-Doped Gallium Lanthanum Sulfide Glass. J. Opt. Soc. Am. B-Opt. Phys. 1999, 16, 308. 
[18] J. H. Zhang, J. Heo, X. J. Zhao, W. Chung. Compositional dependences on the mechanism of upconversion in $\mathrm{Nd}(3+) / \mathrm{Tm}\left(3^{+}\right)$co-doped chalcohalide glasses. J. NonCryst. Solids 2011, 357, 2421.

[19] Y. Guimond, J.-L. Adam, A.-M. Jurdyc, H. L. Ma, J. Mugnier, B. Jacquier. Optical properties of antimony-stabilised sulphide glasses doped with Dy3+ and Er3+ ions. $J$. Non-Cryst. Solids 1999, 256-257, 378.

[20] V. Moizan, V. Nazabal, J. Troles, P. Houizot, J. L. Adam, J. L. Doualan, R. Moncorge, F. Smektala, G. Gadret, S. Pitois, G. Canat. $\mathrm{Er}^{3+}$-doped GeGaSbS glasses for mid-IR fibre laser application: Synthesis and rare earth spectroscopy. Opt. Mater. 2008, 31, 39.

[21] J. Charrier, M. L. Anne, H. Lhermite, V. Nazabal, J. P. Guin, F. Charpentier, T. Jouan, F. Henrio, D. Bosc, J. L. Adam. Sulphide $\mathrm{Ga}_{\mathrm{x}} \mathrm{Ge}_{25-\mathrm{x}} \mathrm{Sb}_{10} \mathrm{~S}_{65}(\mathrm{x}=0,5)$ sputtered films: Fabrication and optical characterizations of planar and rib optical waveguides. J. Appl. Phys. 2008, 104, 073110.

[22] M. L. Anne, J. Keirsse, V. Nazabal, K. Hyodo, S. Inoue, C. Boussard-Pledel, H. Lhermite, J. Charrier, K. Yanakata, O. Loreal, J. le Person, F. Colas, C. Compère, B. Bureau. Chalcogenide glass optical waveguides for infrared biosensing. Sensors 2009, 9, 7398.

[23] M. Guignard, V. Nazabal, F. Smektala, J. L. Adam, O. Bohnke, C. Duverger, A. Moreac, H. Zeghlache, A. Kudlinski, G. Martinelli, Y. Quiquempois. Chalcogenide glasses based on germanium disulfide for second harmonic generation. Adv. Funct. Mater. 2007, 17, 3284.

[24] V. Nazabal, A.-M. Jurdyc, P. Nemec, M.-L. Brandily-Anne, L. Petit, K. Richardson, P. Vinatier, C. Bousquet, T. Cardinal, S. Pechev, J.-L. Adam. Amorphous Tm3+ doped sulfide thin films fabricated by sputtering. Opt. Mater. 2010, 33, 220.

[25] V. G. Truong, A. M. Jurdyc, B. Jacquier, B. S. Ham, A. Q. Le Quang, J. Leperson, V. Nazabal, J. L. Adam. Optical properties of thulium-doped chalcogenide glasses and the uncertainty of the calculated radiative lifetimes using the Judd-Ofelt approach. J. Opt. Soc. Am. B-Opt. Phys. 2006, 23, 2588.

[26] V. G. Truong, Ham, B. S., Jurdyc, A. M., Jacquier, B., Leperson, J., Nazabal, V., Adam, J. L. Relaxation properties of rare-earth ions in sulfide glasses: Experiment and theory. Phys. Rev. B 2006, 74, 184103.

[27] J. Troles, Y. Niu, C. Duverger-Arfuso, F. Smektala, L. Brilland, V. Nazabal, V. Moizan, F. Desevedavy, P. Houizot. Synthesis and characterization of chalcogenide glasses from the system Ga-Ge-Sb-S and preparation of a single-mode fiber at $1.55 \mu \mathrm{m}$. Mater. Res. Bull. 2008, 43, 976.

[28] V. Nazabal, P. Nemec, A. M. Jurdyc, S. Zhang, F. Charpentier, H. Lhermite, J. Charrier, J. P. Guin, A. Moreac, M. Frumar, J. L. Adam. Optical waveguide based on amorphous $\mathrm{Er}^{3+}$ doped Ga-Ge-Sb-S(Se) pulsed laser deposited thin films. Thin Solid Films 2010, 518, 4941.

[29] J. Houska, N. R. Panyala, E. M. Pena-Mendez, J. Havel. Mass spectrometry of nanodiamonds. Rapid Commun.Mass Spectrom. 2009, 23, 1125.

[30] J. Houska, E. M. Pena-Mendez, J. Kolar, M. Frumar, T. Wagner, J. Havel. Laser ablation of AgSbS2 and cluster analysis by time-of-flight mass spectrometry. Rapid Commun.Mass Spectrom. 2009, 23, 1715.

[31] Z. Spalt, M. Alberti, E. Pena-Mendez, J. Havel. Laser ablation generation of arsenic and arsenic sulfide clusters. Polyhedron 2005, 24, 1417.

[32] J. Houska, M. Alberti, J. Havel. Laser ablation synthesis of phosphorus sulphides, selenides and ternary PpSqSer clusters from various precursors. Rapid Commun.Mass Spectrom. 2008, 22, 417. 
[33] G. Ramirez-Galicia, E. M. Pena-Mendez, S. D. Pangavhane, M. Alberti, J. Havel. Mass spectrometry and ab initio calculation of AsSn+ $(n=1-7)$ ion structures. Polyhedron 2010, 29, 1567.

[34] S. D. Pangavhane, L. Hebedova, M. Alberti, J. Havel. Laser ablation synthesis of new phosphorus nitride clusters from alpha-P3N5 via laser desorption ionization and matrix assisted laser desorption ionization time-of-flight mass spectrometry. Rapid Commun.Mass Spectrom. 2011, 25, 917.

[35] N. R. Panyala, V. Prysiazhnyi, P. Slavicek, M. Cernak, J. Havel. Formation of aluminium, aluminium nitride and nitrogen clusters via laser ablation of nano aluminium nitride. Laser desorption ionisation and matrix-assisted laser desorption ionisation timeof-flight mass spectrometry. Rapid Commun.Mass Spectrom. 2011, 25, 1687.

[36] S. D. Pangavhane, P. Nemec, T. Wagner, J. Janca, J. Havel. Laser desorption ionization time-of-flight mass spectrometric study of binary As-Se glasses. Rapid Commun.Mass Spectrom. 2010, 24, 2000.

[37] S. D. Pangavhane, J. Houska, T. Wagner, M. Pavlista, J. Janca, J. Havel. Laser ablation of ternary As-S-Se glasses and time-of-flight mass spectrometric study. Rapid Commun.Mass Spectrom. 2010, 24, 95.

[38] K. V. Klementev. Deconvolution problems in x-ray absorption fine structure spectroscopy. J. Phys. D-Appl. Phys. 2001, 34, 2241.

[39] A. L. Ankudinov, B. Ravel, J. J. Rehr, S. D. Conradson. Real-space multiple-scattering calculation and interpretation of x-ray-absorption near-edge structure. Phys, Rev. B 1998, 58, 7565.

[40] K. Sladkova, J. Houska, J. Havel. Laser desorption ionization of red phosphorus clusters and their use for mass calibration in time-of-flight mass spectrometry. Rapid Commun.Mass Spectrom. 2009, 23, 3114.

[41] A. Gruszecka, M. Szymanska-Chargot, A. Smolira, J. Cytawa, L. Michalak. Role of the support material on laser desorption/ionization mass spectra. Rapid Commun.Mass Spectrom. 2008, 22, 925.

[42] K. Tanaka. Structural phase-transitions in chalcogenide glasses. Phys. Rev. B 1989, 39, 1270.

[43] S. R. Elliott. in Physics of Amorphous Materials, 2nd Edition, Longman, Essex 1995.

[44] C. Julien, S. Barnier, M. Massot, N. Chbani, X. Cai, A. M. Loireaulozach, M. Guittard. RAMAN AND INFRARED SPECTROSCOPIC STUDIES OF GE-GA-AG SULFIDE GLASSES. Mater.Sci. Eng. B 1994, 22, 191.

[45] N. Chbani, A. M. Loireaulozach, F. Keller, S. Benazeth. GLASS-FORMING TENDENCY IN GA-GE-S GLASSES - A STRUCTURAL APPROACH. J. Phys. IV 1994, 4, 113.

[46] B. G. Aitken, C. W. Ponader. Physical Properties and Raman Spectroscopy of Geas Sulphide Glasses. J. Non-Cryst. Solids 1999, 257, 143.

[47] G. Lucovsky, F. L. Galeener, R. C. Keezer, R. H. Geils, H. A. Six. STRUCTURAL INTERPRETATION OF INFRARED AND RAMAN-SPECTRA OF GLASSES IN ALLOY SYSTEM GE1-XSX. Phys. Rev. B 1974, 10, 5134.

[48] S. Sugai. Stochastic random network model in Ge and Si chalcogenide glasses. Phys. Rev. B 1987, 35, 1345.

[49] L. Petit, N. Carlie, F. Adamietz, M. Couzi, V. Rodriguez, K. C. Richardson. Correlation between physical, optical and structural properties of sulfide glasses in the system Ge-SbS. Mater. Chem. .Phys. 2006, 97, 64.

[50] H. Higuchi, R. Kanno, Y. Kawamoto, M. Takahashi, K. Kadano. Local structures of Er3+ containing Ga2S3-GeS2-La2S3 glass. Phys. Chem. Glass. 1999, 40, 122. 
[51] J. H. Song, Y. G. Choi, K. Kadono, K. Fukumi, H. Kageyama, J. Heo. EXAFS investigation on the structural environment of TM3+ in Ge-Ga-S-CsBr glasses. J. NonCryst. Solids 2007, 353, 1251.

[52] Y. G. Choi, J. H. Song, Y. B. Shin, J. Heo. Chemical characteristics of Dy-S bonds in GeAs-S glass. J. Non-Cryst. Solids 2007, 353, 1665.

[53] D. Marchese, A. Jha. The Structural Aspects of the Solubility of Pr3+ Ions in Ges2-Based Glasses. J. Non-Cryst. Solids 1997, 213, 381.

[54] B. G. Aitken, C. W. Ponader, R. S. Quimby. Clustering of Rare Earths in Geas Sulfide Glass. C. R. Chimie 2002, 5, 865.

[55] L. Bigot, A. M. Jurdyc, B. Jacquier, J. L. Adam. Inhomogeneous and Homogeneous Linewidths in Er3+-Doped Chalcogenide Glasses. Opt. Mater. 2003, $24,97$.

[56] M. F. Churbanov. HIGH-PURITY CHALCOGENIDE GLASSES AS MATERIALS FOR FIBER OPTICS. J. Non-Cryst. Solids 1995, 184, 25.

[57] M. L. Feng, Z. L. Xie, X. Y. Huang. Two Gallium Antimony Sulfides Built on a Novel Heterometallic Cluster. Inorg. Chem. 2009, 48, 3904.

[58] A. Povolotskiy, T. Ivanova, A. Manshina, Y. Tver'Yanovich, S. K. Liaw, C. L. Chang. Er3+ as glass structure modifier of Ga-Ge-S chalcogenide system. Appl. Phys. A 2009, 96, 887.

[59] S. W. Hunsucker, R. C. Watson, B. M. Tissue. Characterization of inorganic coordination complexes by matrix-assisted laser desorption/ionization mass spectrometry. Rapid Commun.Mass Spectrom. 2001, 15, 1334.

[60] N. Aminlashgari, M. Hakkarainen. Surface Assisted Laser Desorption Ionization-Mass Spectrometry (SALDI-MS) for Analysis of Polyester Degradation Products. J. Am. Soc. Mass Spectrom. 2012, 23, 1071.

[61] Y. Z. Li, J. Y. Huang, R. T. McIver, J. C. Hemminger. CHARACTERIZATION OF THIOL SELF-ASSEMBLED FILMS BY LASER DESORPTION FOURIERTRANSFORM MASS-SPECTROMETRY. J. Am. Chem. Soc. 1992, 114, 2428. 


\section{Tables}

Table 1. Summary of positively charged $\mathrm{Ga}_{m} \mathrm{Ge}_{n} \mathrm{Sb}_{o} \mathrm{~S}_{p}{ }^{+}$species identified in mass spectra of $\mathrm{Ga}_{5} \mathrm{Ge}_{20} \mathrm{Sb}_{10} \mathrm{~S}_{65}$ glass doped with erbium (0.05, 0.1, 0.5 wt. \%). $m$ indicate number of gallium atoms in $\mathrm{Ga}_{m} \mathrm{Ge}_{n} \mathrm{Sb}_{o} \mathrm{~S}_{p}$ clusters. ${ }^{+/}$indicate that the species was observed in both positive and negative ion mode.

Table 2. Summary of negatively charged $\mathrm{Ga}_{m} \mathrm{Ge}_{n} \mathrm{Sb}_{o} \mathrm{~S}_{p}{ }^{-}$species identified in mass spectra of $\mathrm{Ga}_{5} \mathrm{Ge}_{20} \mathrm{Sb}_{10} \mathrm{~S}_{65}$ glass doped with erbium (0.05, 0.1, 0.5 wt. \%). $m$ indicate number of gallium atoms in $\mathrm{Ga}_{m} \mathrm{Ge}_{n} \mathrm{Sb}_{o} \mathrm{~S}_{p}$ clusters.

Table 3. Survey of the overlapped clusters identified in negative and positive ion modes. Estimated contribution of the secondary species in relative \% with respect to main one is given. 
Table 1.

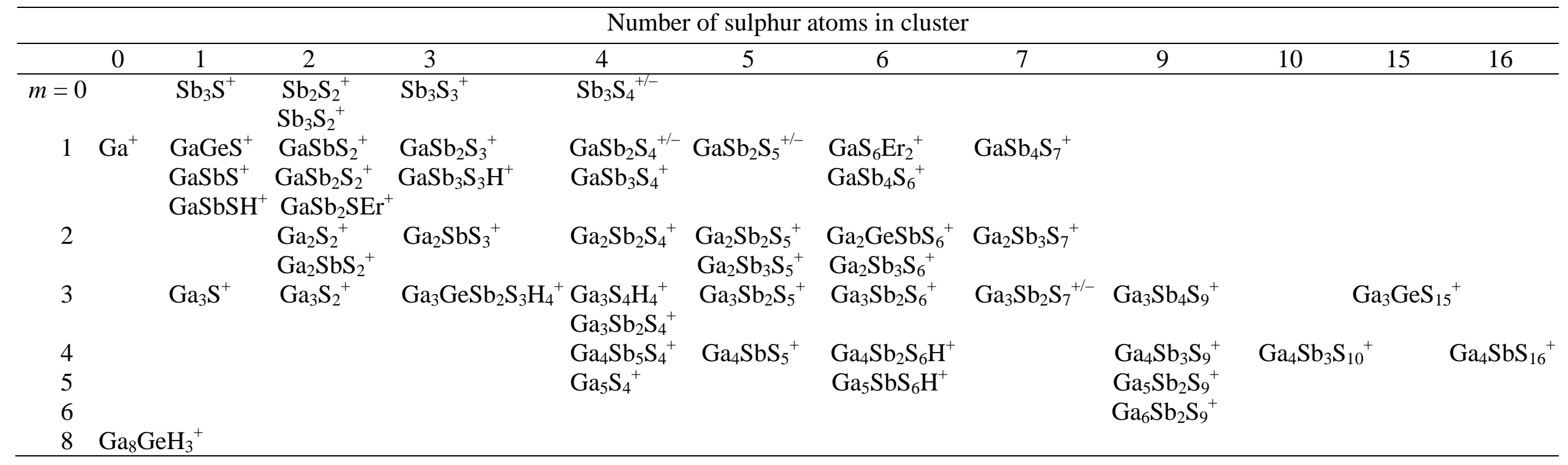


Table 2.

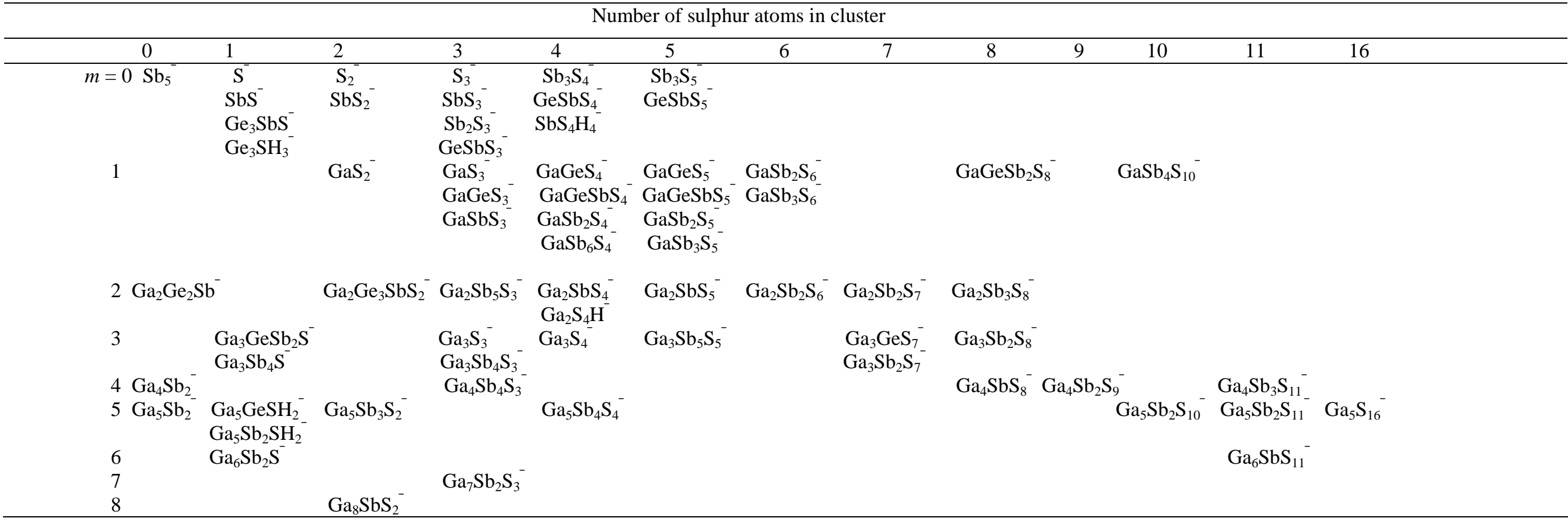


Table 3.

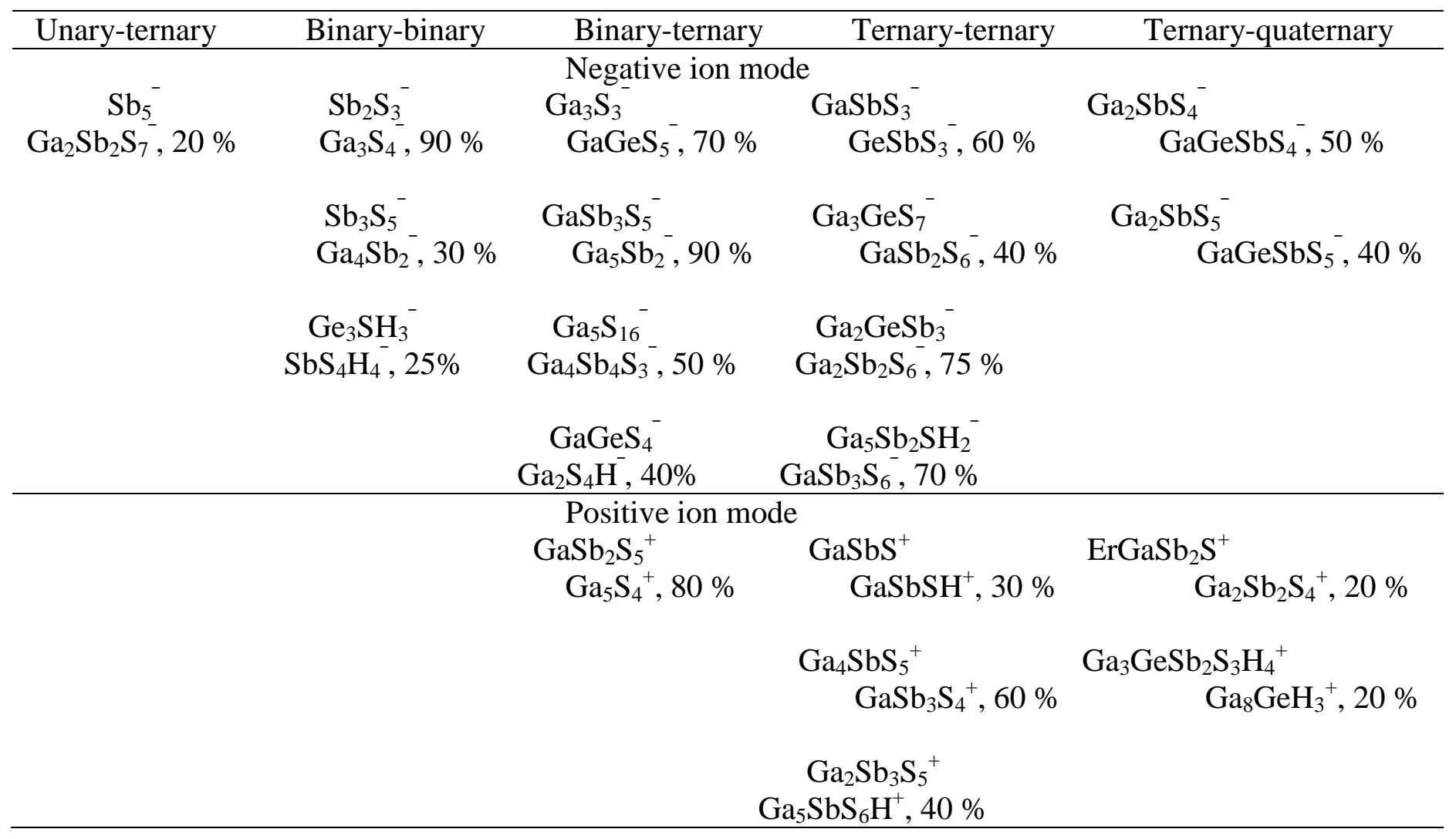




\section{Figures captions}

Figure 1. (A) Raman spectra of Ga-Ge-(Sb)-S bulk glasses. (B) Radial distribution function curves of $\mathrm{Er}^{3+}$ ions in $\mathrm{Ga}_{5} \mathrm{Ge}_{20} \mathrm{Sb}_{10} \mathrm{~S}_{65}$ (phase shifts not corrected) and results of the fitting (red) on the first coordination shell around $\mathrm{Er}^{3+}$ ions.

Figure 2. Full scale mass spectra show laser energy effect for $\mathrm{Ga}_{5} \mathrm{Ge}_{20} \mathrm{Sb}_{10} \mathrm{~S}_{65}$ glass doped with erbium (0.05 wt. \%). (A) Mass range 0-1200; the spectra were normalized to $1182 \mathrm{mV}$. Conditions: linear positive ion mode, laser energy 90, 110, 130, and 150 a.u. (B) Full scale mass spectra show laser energy effect for $\mathrm{Ga}_{5} \mathrm{Ge}_{20} \mathrm{Sb}_{10} \mathrm{~S}_{65}$ glass doped with erbium (0.5 wt. \%) Conditions: linear positive ion mode, laser energy 50, 60, 70, 80, 90 a.u., mass spectra were normalized to $2100 \mathrm{mV}$.

Figure 3. Full scale mass spectra show results of analysis for $\mathrm{Ga}_{5} \mathrm{Ge}_{20} \mathrm{Sb}_{10} \mathrm{~S}_{65}$ glass doped with erbium (0.1 wt. \%). (A) Mass range up to $\mathrm{m} / \mathrm{z} 500$. (B) Mass range over $\mathrm{m} / \mathrm{z} 500$. Conditions: linear positive ion mode, laser energy 90 a.u.

Figure 4. Selected parts of experimental mass spectra measured for $\mathrm{Ga}_{5} \mathrm{Ge}_{20} \mathrm{Sb}_{10} \mathrm{~S}_{65}$ glass doped with erbium (0.1 wt. \%) and comparison with theoretical models at lower, middle, and higher $\mathrm{m} / \mathrm{z}$ values among whole range of experimental mass spectra. Conditions: linear positive ion mode, laser energy 90 a.u.

Figure 5. Full scale mass spectra show results of analysis for $\mathrm{Ga}_{5} \mathrm{Ge}_{20} \mathrm{Sb}_{10} \mathrm{~S}_{65}$ glass doped with erbium (0.5 wt. \%). (A) Mass range up to $\mathrm{m} / \mathrm{z} 500$. (B) Mass range over $\mathrm{m} / \mathrm{z} 500$. Conditions: linear negative ion mode, laser energy 80 a.u.

Figure 6. (A) Selected parts of experimental mass spectra measured for $\mathrm{Ga}_{5} \mathrm{Ge}_{20} \mathrm{Sb}_{10} \mathrm{~S}_{65}$ glass doped with erbium (0.5 wt. \%) and comparison with theoretical models at lower, middle, and higher $\mathrm{m} / \mathrm{z}$ values among whole range of experimental mass spectra. (B) Theoretical models and experimental mass spectra for selected Ge-based species Conditions: linear negative ion mode, laser energy 80 a.u. 
Figure 1 (A)

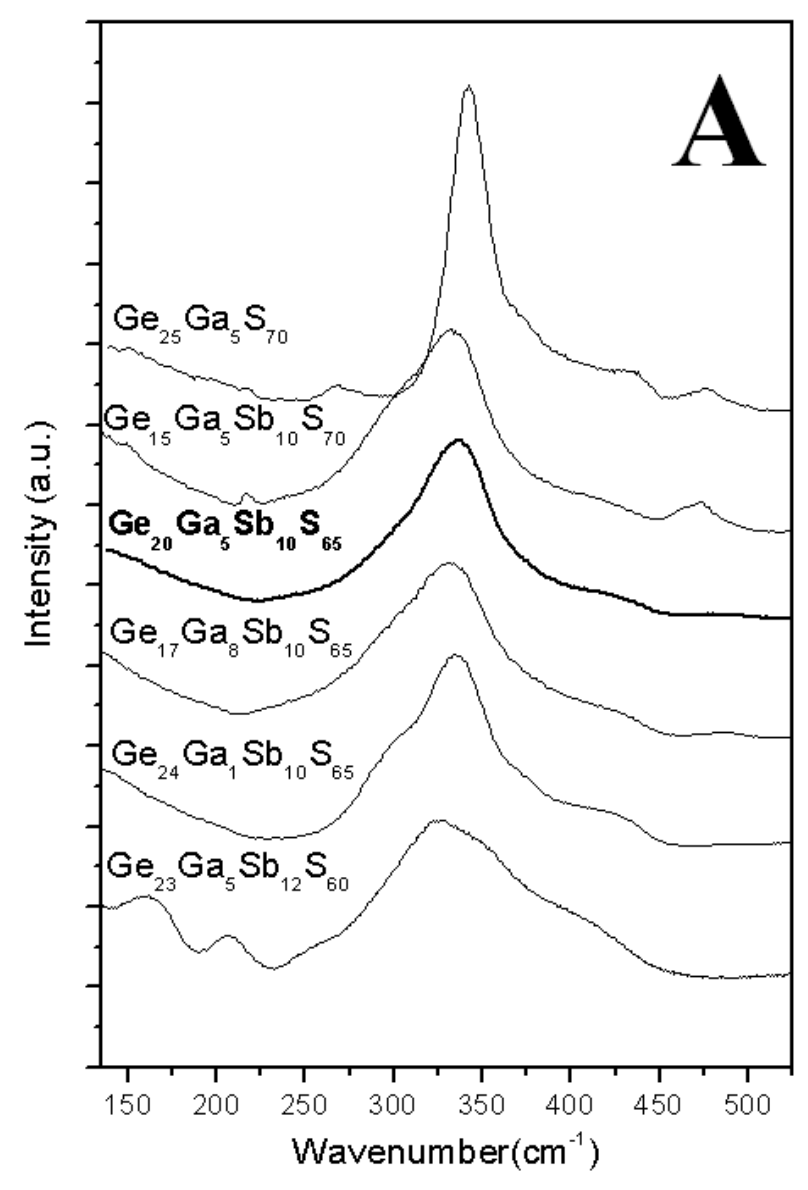


Figure 1 (B)

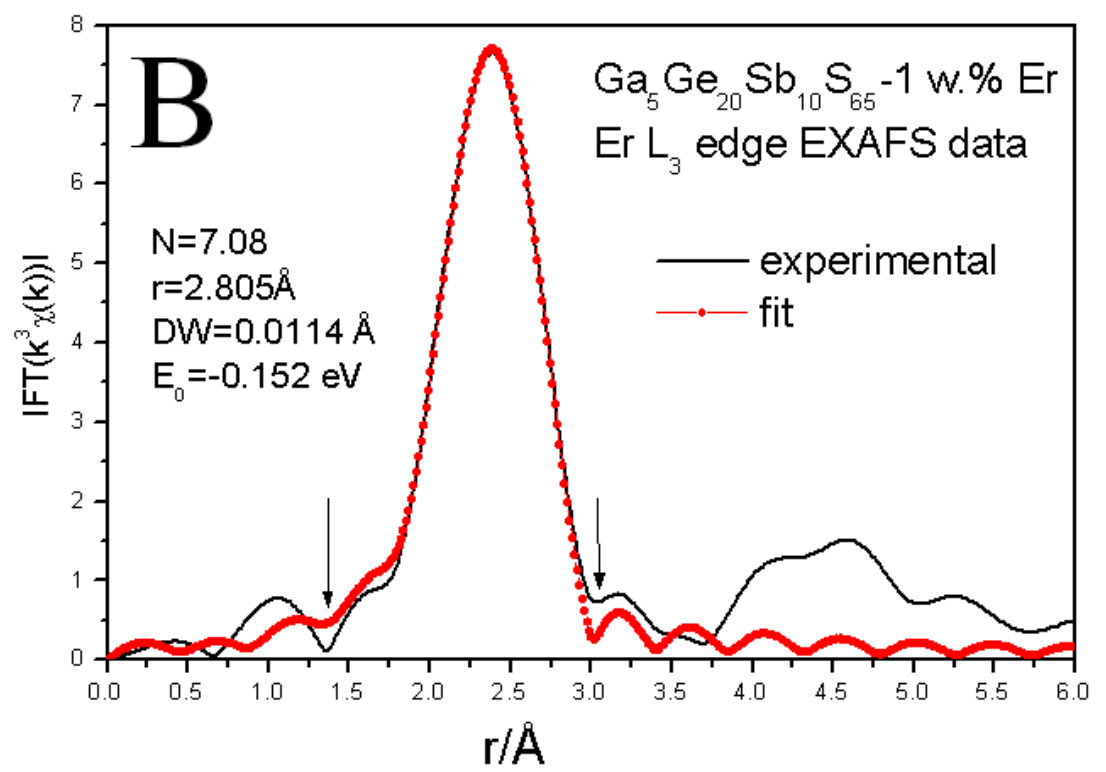


Figure 2 (A)

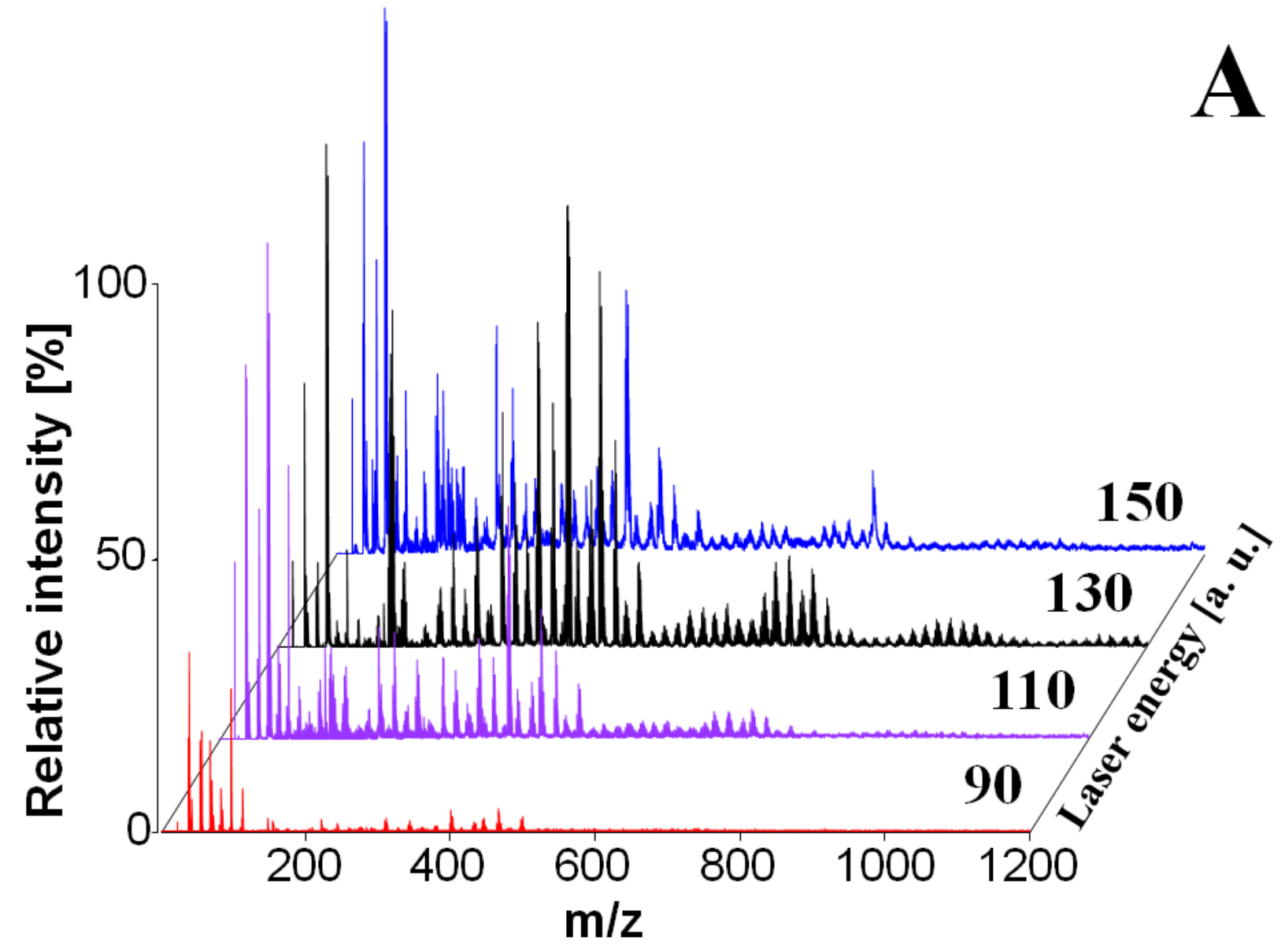


Figure 2 (B)

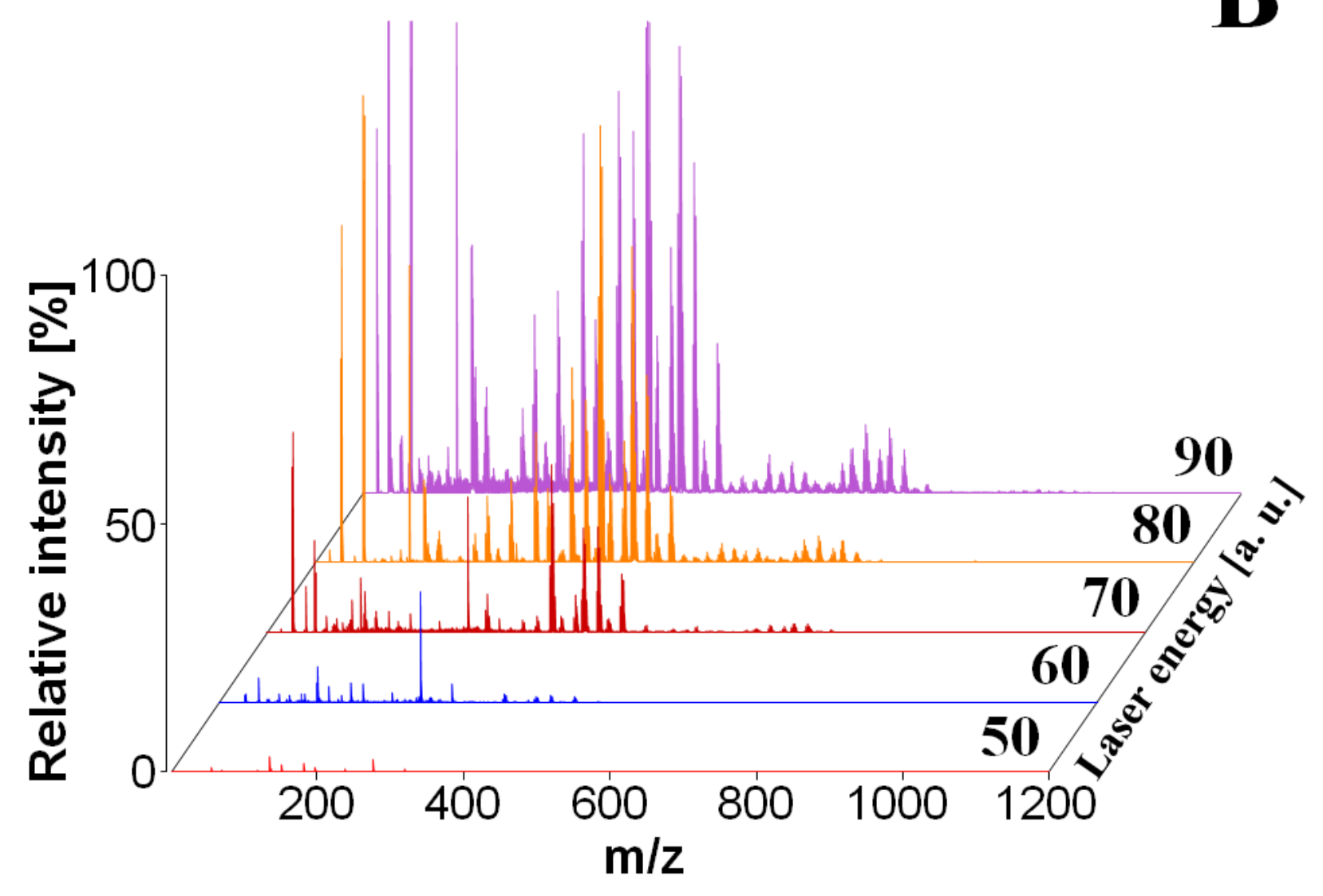


Figure 3 (A)

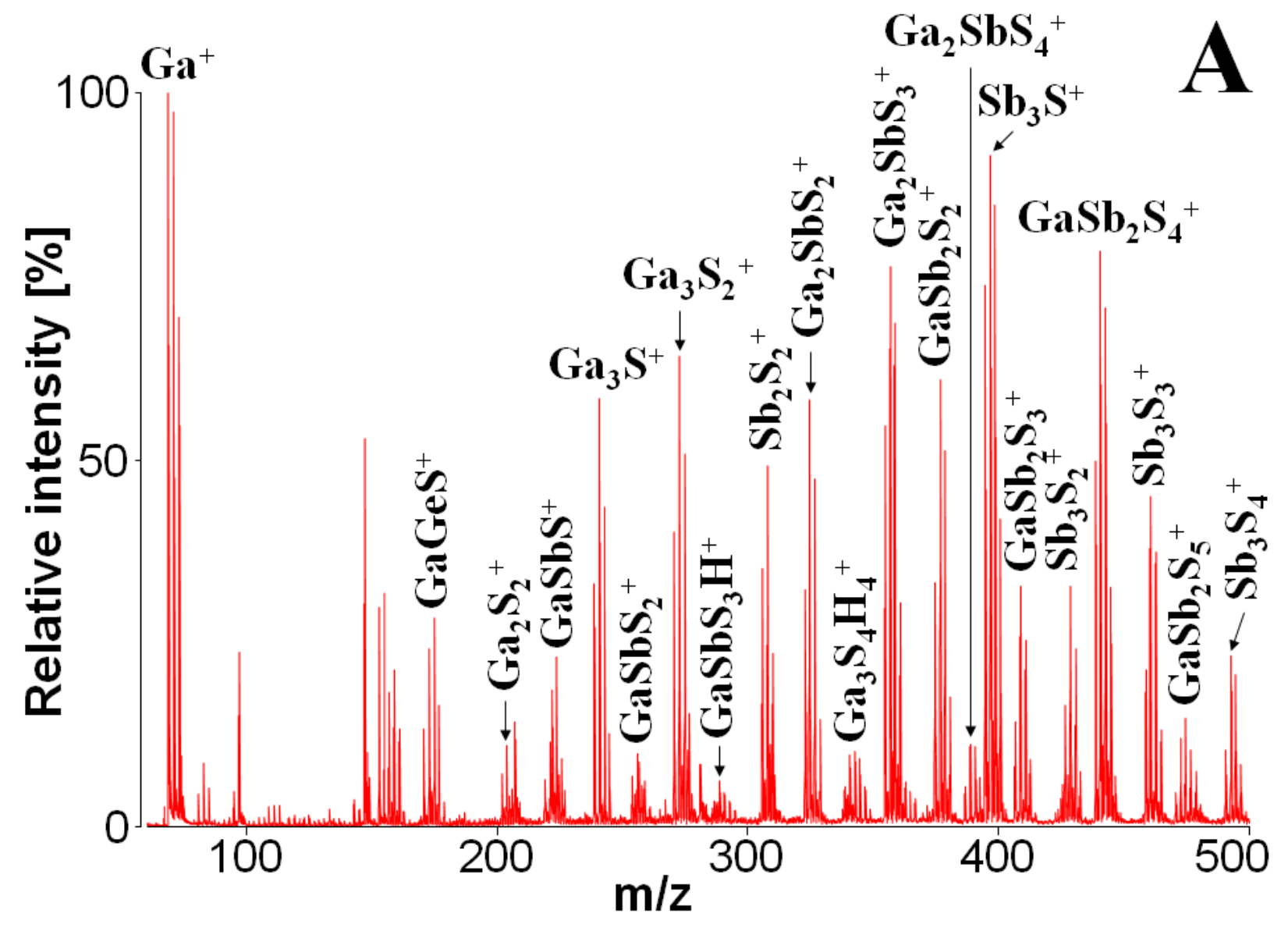


Figure 3 (B)

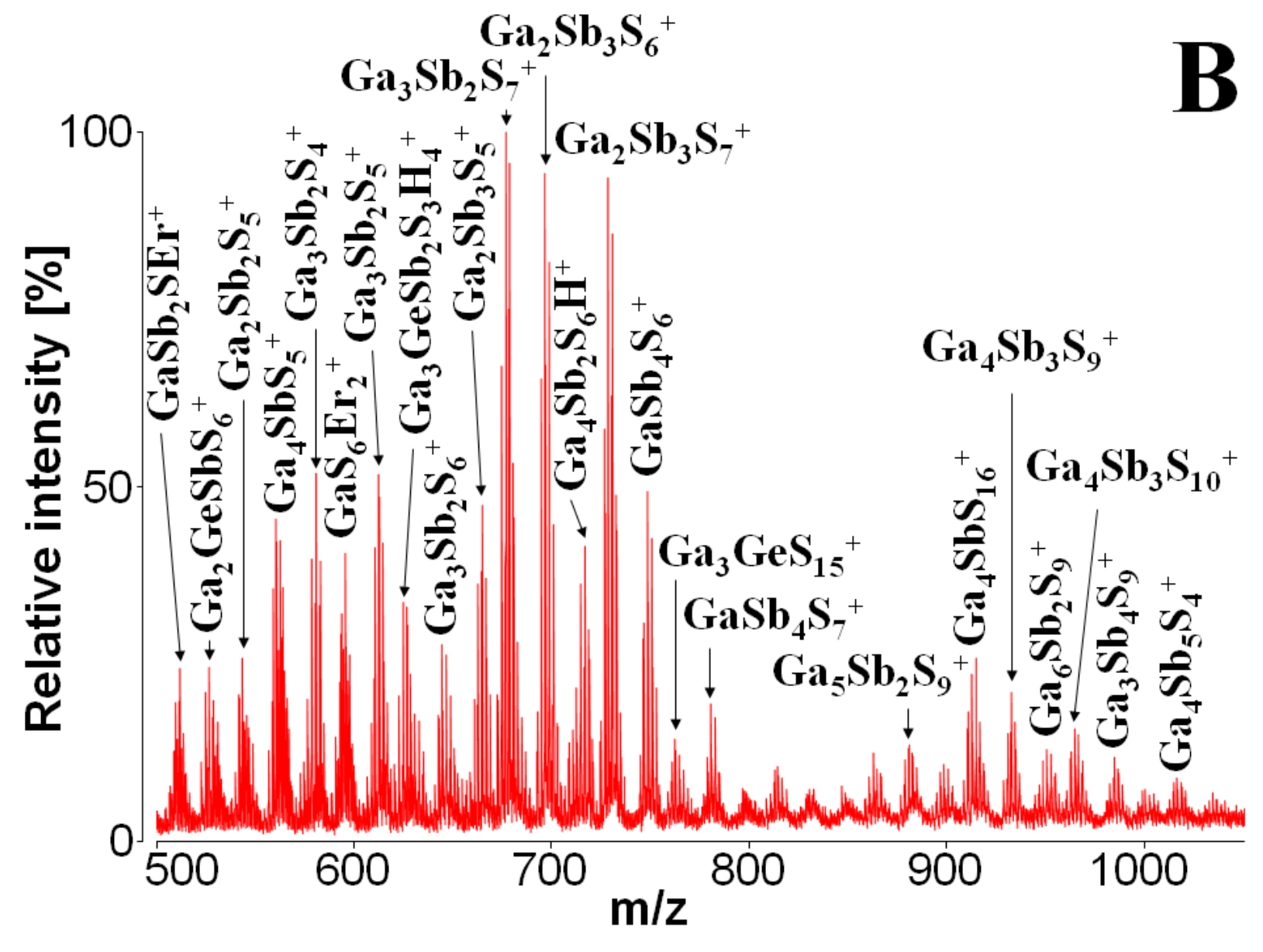


Figure 4

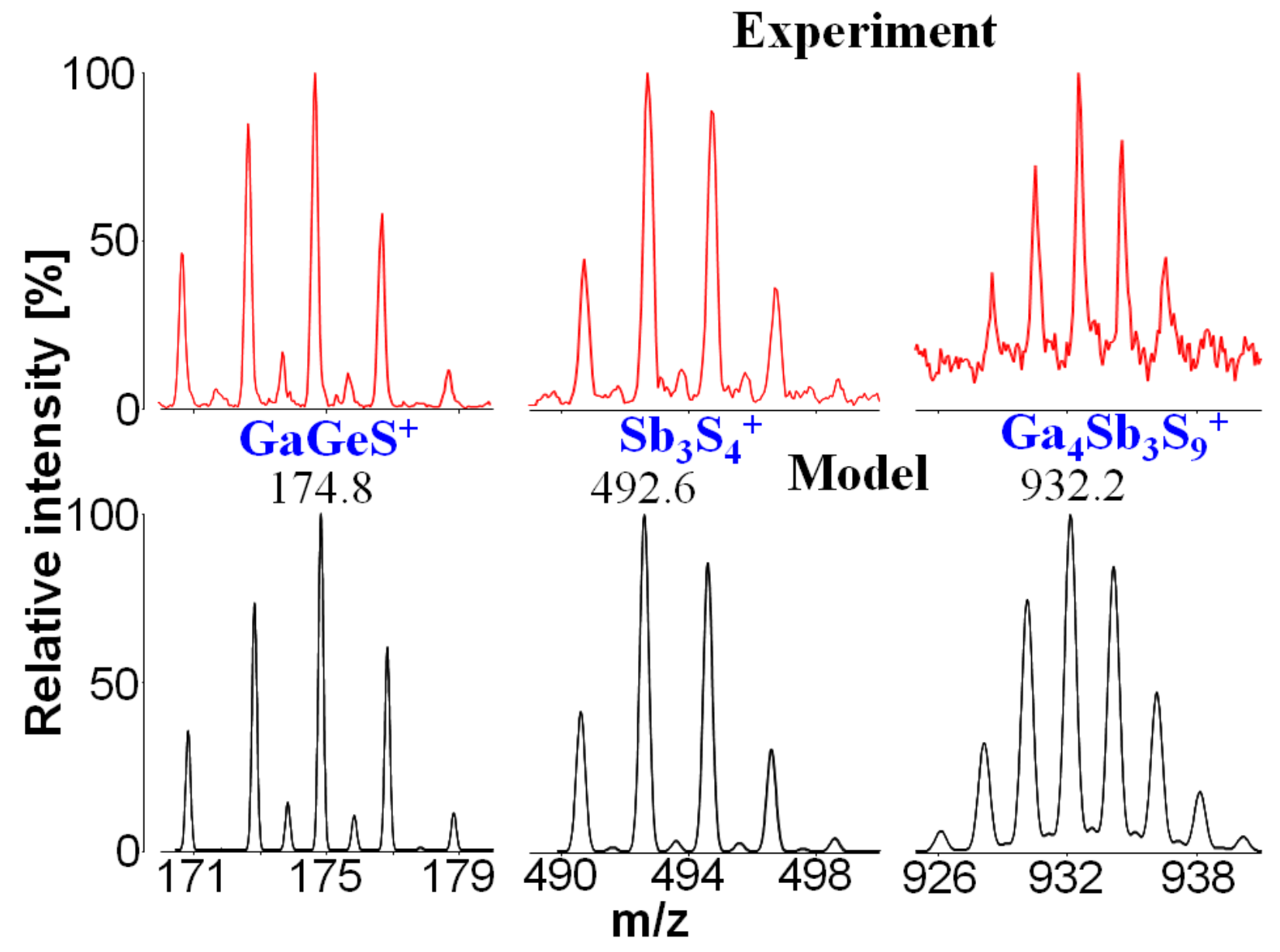


Figure 5 (A)

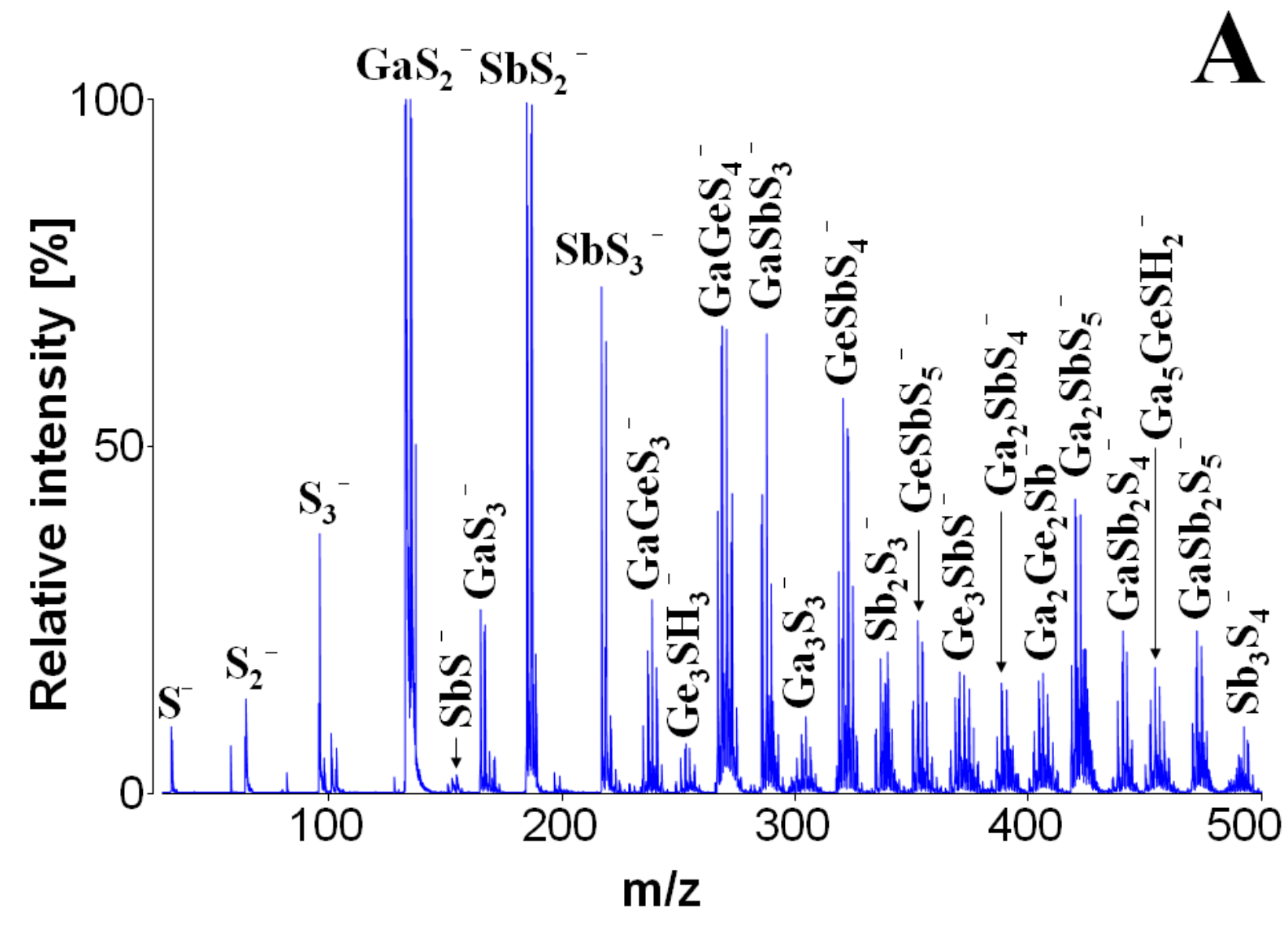


Figure 5 (B)

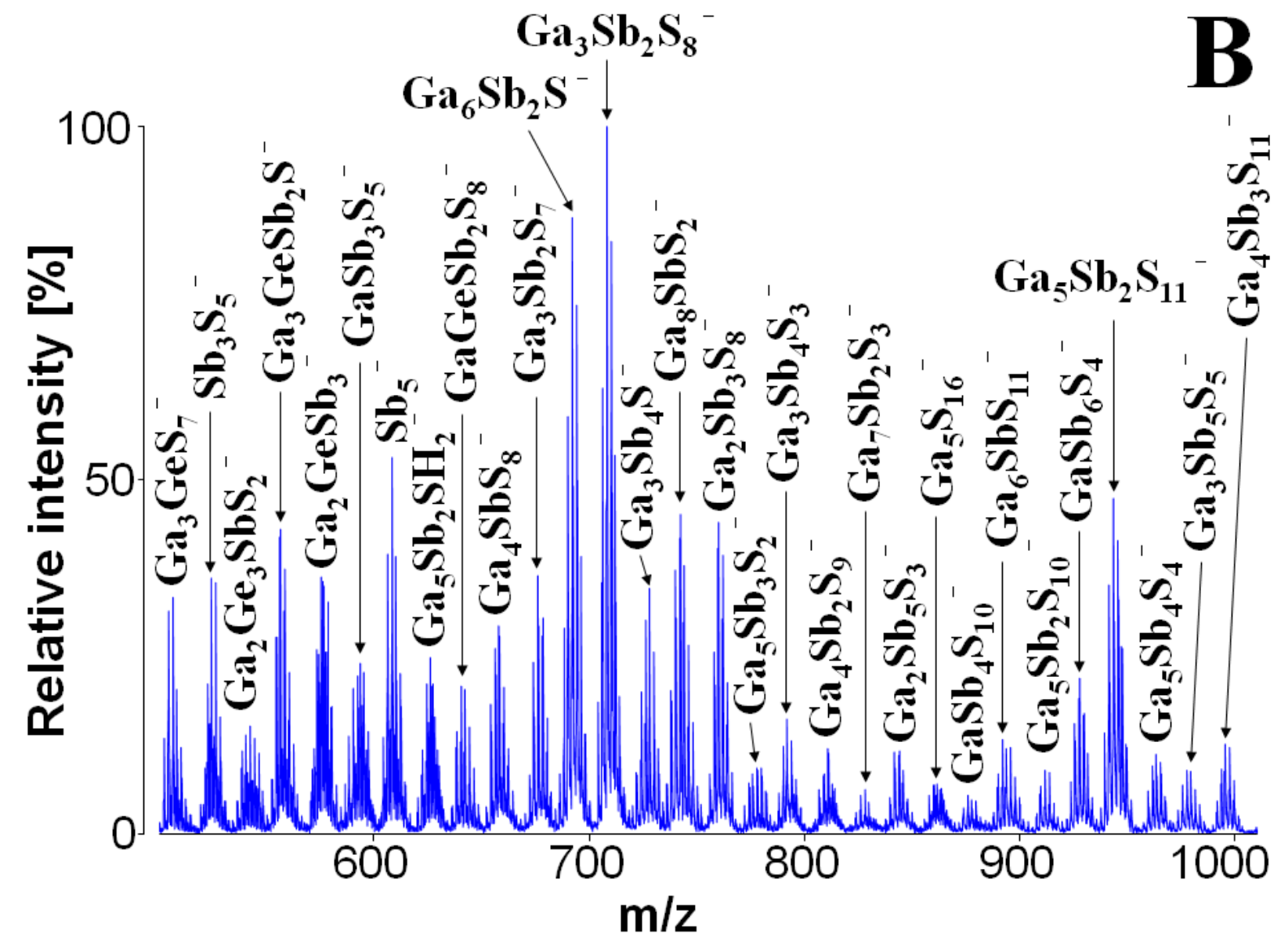


Figure 6 (A)

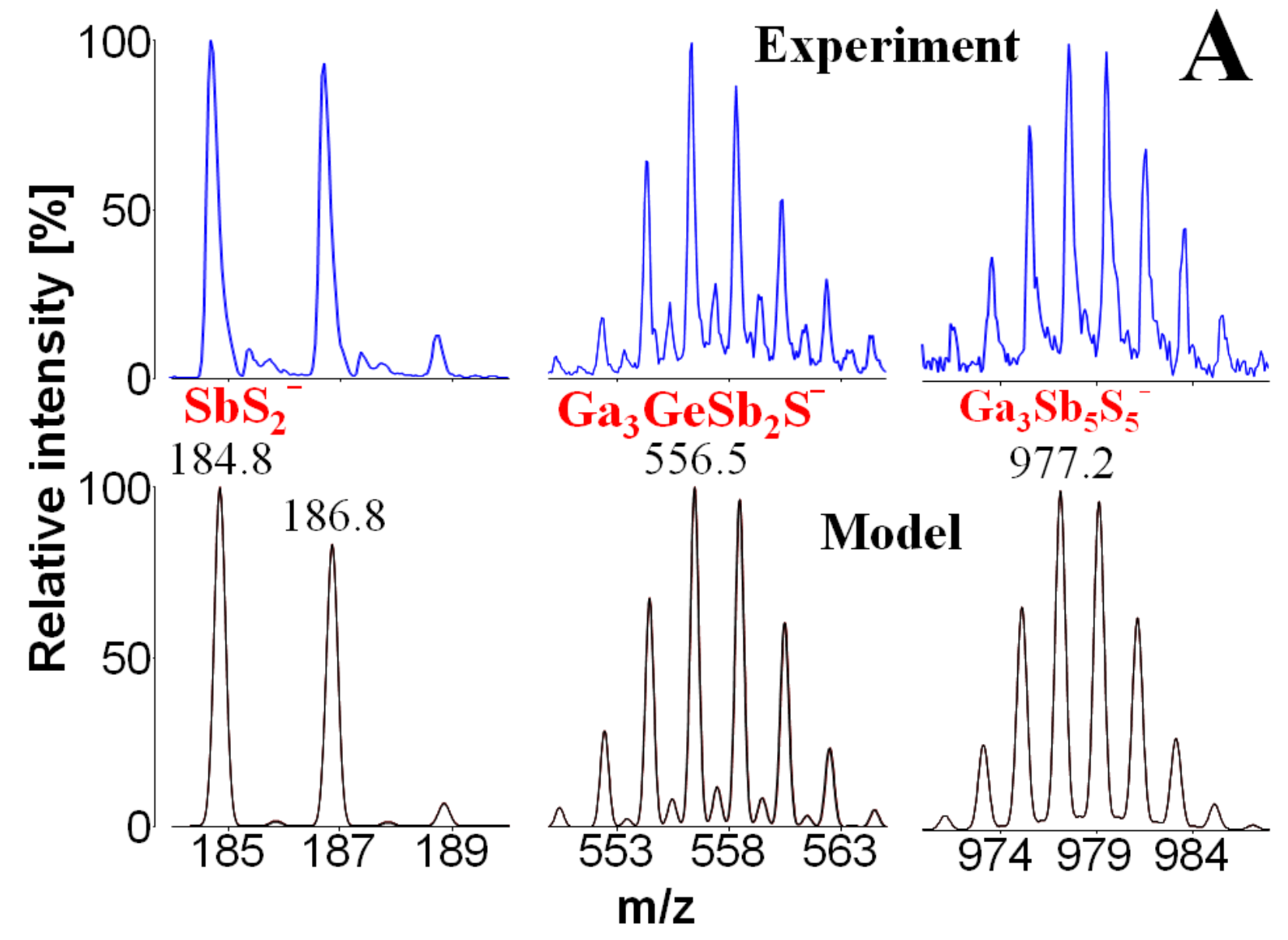


Figure 6 (B)

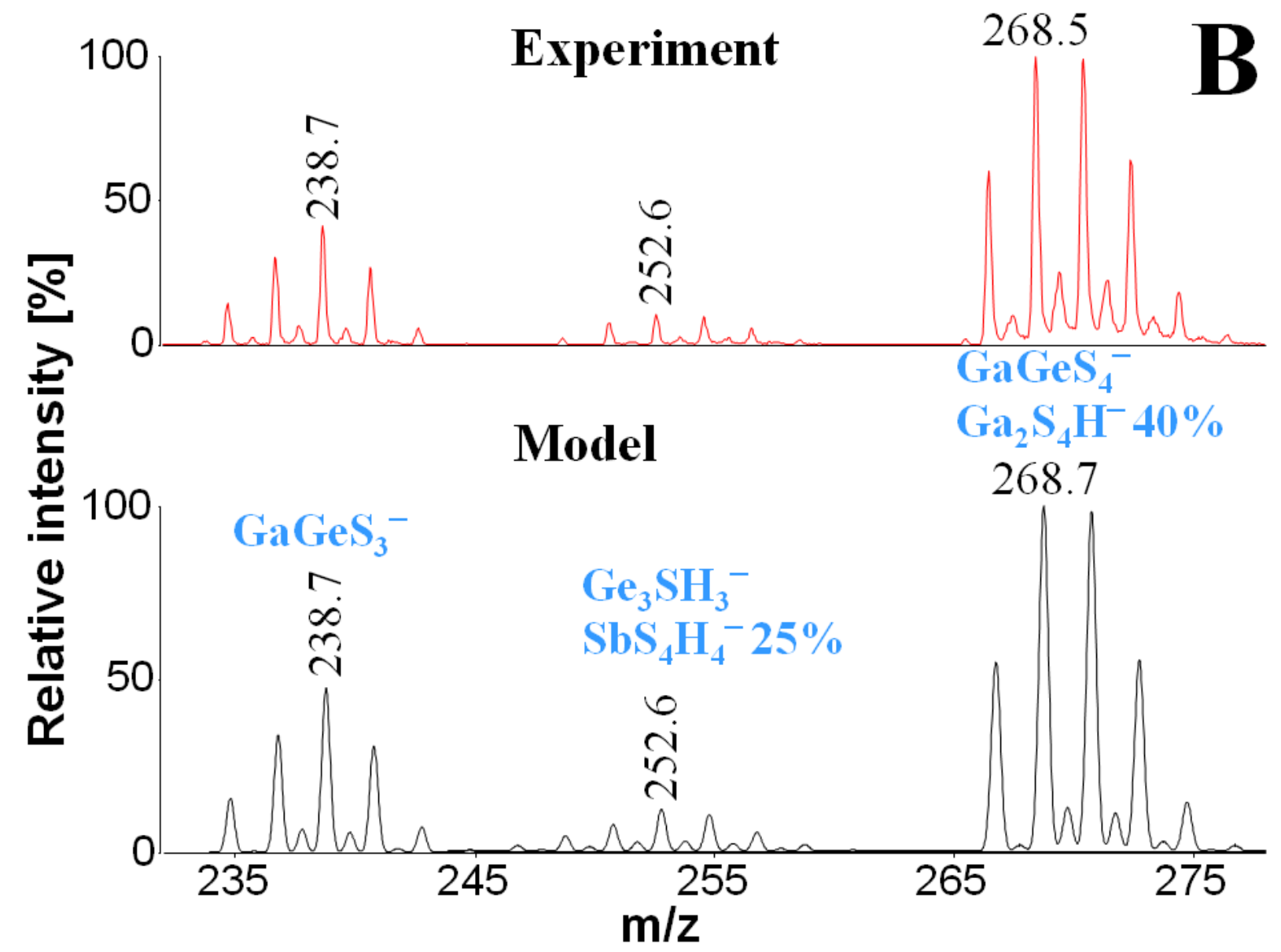

